ISSN 1392-3196 / e-ISSN 2335-8947

Zemdirbyste-Agriculture, vol. 103, No. 1 (2016), p. 67-76

DOI 10.13080/z-a.2016.103.009

\title{
Role of inoculation with multi-trait rhizobacteria on strawberries under water deficit stress
}

\author{
Ümmügülsüm ERDOGAN ${ }^{1}$, Ramazan ÇAKMAKÇI ${ }^{1}$, Atafeh VARMAZYARI ${ }^{1}$, \\ Metin TURAN ${ }^{2}$, Yaşar ERDOGAN ${ }^{1}$, Nurgül KITIR ${ }^{2}$ \\ ${ }^{1}$ Atatürk University \\ 25900 Erzurum, Turkey \\ E-mail: gerdogan@atauni.edu.tr \\ ${ }^{2}$ Yeditepe University \\ Kayısdagi, 34755 Istanbul, Turkey
}

\begin{abstract}
This study was conducted during 2011 and 2012 to evaluate the effect of 1-aminocyclopropane-1-carboxylate (ACC) deaminase-containing, $\mathrm{N}_{2}$-fixing and P-solubilizing bacteria on the yield and morpho-physiological parameters of strawberry. A total of 8 applications at the trial set, with four water regimes were randomly distributed into the pots. The diminishing water supply caused a gradual decrease in the plant growth, chlorophyll content and berry yield, accompanied by increasing activities of drought stress markers such as total phenolics content (TPC), trolox equivalent antioxidant capacity (TEAC), malondialdehyde (MDA) content, hydrogen peroxide $\left(\mathrm{H}_{2} \mathrm{O}_{2}\right)$, glutathione reductase (GR), glutathione S-transferase (GST), catalase (CAT), peroxidase (POD), superoxide dismutase (SOD) and ascorbate peroxidase (APX) in the leaves of strawberry. The multi-trait bacteria also increased plant growth and yield as well as TPC, TEAC, antioxidant enzymes (GR, GST, CAT, POD, SOD and APX) activity, phytohormone (GA, SA and IAA) and the contents of N, P, K, Ca, Fe, Mn, $\mathrm{Zn}$ and $\mathrm{Cu}$, but decreased MDA and $\mathrm{H}_{2} \mathrm{O}_{2}$ contents which may contribute in part to activation of physiological and biochemical processes involved in the alleviation of the effect of drought stress.
\end{abstract}

Key words: drought stress, enzyme activity, Fragaria $\times$ ananassa, nutrient uptake, plant growth-promoting bacteria.

\section{Introduction}

Strawberry (Fragaria $\times$ ananassa Duch.) is a shallow-rooted crop very sensitive to soil water deficit. Strawberry plants are very sensitive to drought stress during flowering and fruit ripening. Drought stress constitutes a major threat for crop yield worldwide and water shortage considerably lowers plant dry matter production, and thus the final yield. On the other hand, to limit the amounts of water used for several horticultural crops, water deficit irrigation has been seen as a potential alternative for new cultivation systems (Bordonaba, Terry, 2010). In strawberry plants regulated deficit irrigation technique is generally associated with reduction in fruit size and yield; (Liu et al., 2007). Despite this fact, other attributes, related to fruit quality increased (Terry et al., 2007; Heiadari, Golpayegani, 2012).

Plant growth-promoting rhizobacteria (PGPR) generally improve the nutritional, biochemical, physiological and morphological responses of many plants and, thus, it enhances the plant resistance to biotic and abiotic stresses. Plants inoculated with PGPR strains and exposed to water stress showed a better water status than control plants, alleviated drought stress by using alternative mechanisms, and higher yields under drought conditions were obtained (Compant et al., 2010). Like many other environmental factors, drought also induces accelerated ethylene production in plant tissues which leads to abnormal growth of a plant (Saleem et al., 2007; Bresson et al., 2013). Inoculation of crops with ACC deaminase-containing PGPR may assist plant growth by alleviating deleterious effects of stress ethylene.

GST, GR, SOD, CAT and APX can protect cells from a wide variety of biotic and abiotic stresses (Gill, Tuteja, 2010), and several growth and development related events. Alleviation of the oxidative damage and sustaining of growth under stress was correlated with the enhancement of GR activities and GR activity increased under drought stress (Nikolaeva et al., 2010). Under drought stress, the activities of POD, SOD, CAT, APX and GR increased consistently (Wu et al., 2006). Recently, our studies demonstrated for the first time that PGPR could enhance GR and GST activities, together with the growth of plants (Çakmakçı et al., 2007; 2009). Malondialdehyde (MDA) and hydrogen peroxide $\left(\mathrm{H}_{2} \mathrm{O}_{2}\right)$ contents usually serve as physiological indices of plant stress response. As the intensity of drought increased, both $\mathrm{H}_{2} \mathrm{O}_{2}$ and MDA levels increased indicating the oxidative stress. Activities of SOD, POD and CAT antioxidant enzymes and MDA content are suitable indicators to evaluate the degree of drought tolerance in crop plants (Zhang et al., 2011) 
The use of beneficial bacteria as agricultural inputs for increasing crop production needs the selection of competent rhizobacteria with plant growth-promoting attributes, irrigation water deficit has been seen as a potential alternative for considerably new cultivation systems which could not only reduce water usage but also increase the water use efficiency in crops. Another alternative strategy is to induce stress tolerance by using beneficial microorganisms. Also, a few studies have focused on the effects of free-living rhizospheric microorganisms on the amelioration of water stress in plants. However, there is still a lack of information about morpho-physiological behaviour of different strawberry cultivars under limited water availability. Therefore, this study was conducted in order to investigate the effect of different 1-aminocyclopropane-1-carboxylate (ACC) deaminase-containing, auxin (IAA)-producing, $\mathrm{N}_{2}$-fixing and/or P-solubilizing bacterial species on the growth, yield, selected morphological and physiological parameters, indicative of oxidative stress (MDA and $\mathrm{H}_{2} \mathrm{O}_{2}$ ), and antioxidant enzymes (GR, GST, CAT, POD, SOD and APX) in the leaves of strawberry cultivars grown in a non-sterile soil, under well-watered and water-deficit stress conditions.

\section{Materials and methods}

Plant material and growth conditions. The trial was organized as one set for strawberry cultivar 'Aromas' and was carried out for two years (2011-2012) in a greenhouse of Ispir Vocational School in Erzurum, Turkey. Experiments were conducted to study the effect of irrigation regimes and plant growth-promoting rhizobacteria (PGPR) on growth and growth characters of strawberry. The experiment was conducted using a completely randomized factorial design. Treatments with four replicates were as follows: 1) control (without bacteria inoculation), 2) Paenibacillus polymyxa RC05, 3) P. polymyxa RC35, 4) Pseudomonas fluorescens RC77, 5) P. fluorescens RC86, 6) Pseudomonas putida RC06, 7) P. putida 29/2 and 8) Rhodococcus erythropolis RC9. There were eight treatments, four water regimes $(25,50,75$ and $100 \%$ of water-holding capacity (WHC), and four replicates (each having five plants) totalling 640 plastic containers. For this experiment, pure cultures were grown in $50 \%$ strength tryptic soy broth (Merck, Germany) on a rotary shaker $\left(120 \mathrm{rpm}, 25^{\circ} \mathrm{C}\right)$ for 3 days. Bacteria were then harvested by centrifugation (ca. 3000 $\times \mathrm{g}$ for $10 \mathrm{~min}$ ), washed and re-suspended in a $10 \mathrm{mM}$ sterile phosphate buffer (SPB), $\mathrm{pH} 7$ to a density of $10^{9}$ cfu $\mathrm{mL}^{-1}$ for the bacterial strains. Young rooted cuttings of uniform height were inoculated with each of the PGPR strains. The bacterial inoculation involved dipping the root system of the saplings into a suspension of each PGPR strain for $60 \mathrm{~min}$, prior to planting. Control plants received $5 \mathrm{~mL}$ of diluted SPB with no bacteria.

Bacterial strains. We selected seven different potential PGPR from a pool of 460 rhizobacterial isolates based on their 1-aminocyclopropane-1-carboxylate (ACC) deaminase-containing, auxin (IAA)-producing, $\mathrm{N}_{2}$-fixing and P-solubilizing strains (Table 1). They were simultaneously tested for their growth and yield increasing potential under greenhouse conditions by conducting pot experiments in two years. The bacterial strains $P$. polymyxa $\mathrm{RC} 35, P$. fluorescens $\mathrm{RC} 77$ and $R$. erythropolis RC9 were isolated from the rhizosphere of wild red raspberries (Çakmakçı et al., 2007; 2009), and P. polymyxa RC05 and P. putida RC06 were isolated from wheat, and the other two strains (P. fluorescens RC86 and $P$. putida 29/2) were isolated from the rhizosphere of tea (Çakmakçı et al., 2010).

Table 1. Biochemical characteristics of the bacterial strains tested

\begin{tabular}{|c|c|c|c|c|}
\hline Bacterial strains & $\begin{array}{c}\text { IAA-production } \\
\mu \mathrm{g} \mathrm{mL}^{-1} \\
\mathrm{OD}_{600} \mathrm{unit}^{-1}\end{array}$ & $\begin{array}{c}\text { Nitrogenase activity } \\
\mathrm{nmol} \mathrm{C}_{2} \mathrm{H}_{4} \\
10^{7} \mathrm{cfu} \mathrm{h}^{-1}\end{array}$ & $\begin{array}{l}\text { P-solubilization } \\
\mu \mathrm{g} \mathrm{P} \mathrm{mL} \mathrm{mL}^{-1} \mathrm{~d}^{-1}\end{array}$ & $\begin{array}{c}\text { ACC deaminase activity } \\
\text { nmol } \alpha \text {-ketobutyrate } \\
\mathrm{mg}^{-1} \text { protein } \mathrm{h}^{-1}\end{array}$ \\
\hline Paenibacillus polymyxa RC05 & $32.8 \pm 2.6$ & $0.68 \pm 0.14$ & $10.07 \pm 0.9$ & $682.1 \pm 33.7$ \\
\hline Paenibacillus polymyxa RC35 & $31.6 \pm 2.4$ & $0.65 \pm 0.11$ & $11.9 \pm 1.1$ & $441.3 \pm 21.2$ \\
\hline Pseudomonas fluorescens RC77 & $32.4 \pm 2.9$ & $0.79 \pm 0.15$ & $39.4 \pm 1.7$ & $364.4 \pm 26.8$ \\
\hline Pseudomonas fluorescens RC86 & $30.6 \pm 1.9$ & $0.48 \pm 0.07$ & $36.7 \pm 1.8$ & $245.4 \pm 19.5$ \\
\hline Pseudomonas putida RC06 & $26.8 \pm 2.7$ & $0.54 \pm 0.08$ & $17.6 \pm 1.3$ & $746.2 \pm 47.8$ \\
\hline Pseudomonas putida 29/2 & $16.4 \pm 1.4$ & $0.47 \pm 0.12$ & $28.9 \pm 1.8$ & $332.6 \pm 17.4$ \\
\hline Rhodococcus erythropolis RC9 & $22.6 \pm 1.5$ & $0.55 \pm 0.11$ & $27.8 \pm 1.5$ & $577.8 \pm 26.7$ \\
\hline
\end{tabular}

Note. Data were means \pm standard error of three replicates, IAA (auxin)-production in average $72 \mathrm{~h}$ pure cultures, ACC 1-aminocyclopropane-1-carboxylate.

Pot experiments were conducted on strawberry (Fragaria $\times$ ananassa Duch. cv. 'Aromas') well supplied with water $(100 \%$ water-holding capacity), under mild water stress ( $75 \%$ of WHC), under moderate water stress (50\% of WHC) and severe water stress (25\% of WHC). At the beginning of the experiments, pots were water saturated and allowed to drain freely until there was no change in the weight. The difference between this weight and soil dry weight was used to calculate $100 \%$ of WHC. Also, water regimes were defined as a percentage of WHC of the cultivation substrate which was initially determined gravimetrically in the laboratory. The various irrigation regimes were initiated during the first three weeks after planting to allow successful establishment of the PGPR growth at $90 \%$ of WHC. Thereafter, the water regimes were maintained gravimetrically by daily irrigation. The soil water content was daily measured with the ThetaProbe ML2 (Delta-T Devices, UK) before rewatering. The amount of water lost was added to each pot in order to keep the soil water content at the desired level of WHC. All plants were grown in a greenhouse under a day/night cycle of $16 / 8 \mathrm{~h}$ natural light, $25 / 18^{\circ} \mathrm{C}$ and $60 / 70 \%$ relative humidity.

Preparation of the homogenate, determination of enzyme activities and protein concentrations. Tissue samples were washed three times with $50 \mathrm{mM}$ Tris- $\mathrm{HCl}+$ $0.1 \mathrm{M} \mathrm{Na}_{2} \mathrm{SO}_{4}$ (pH 8.0), each was homogenized by liquid nitrogen, transferred to $100 \mathrm{mM} \mathrm{PVP}+10 \mathrm{mM} \mathrm{NaN}_{3}+$ 
$50 \mathrm{mM}$ Tris- $\mathrm{HCl}+0.1 \mathrm{M} \mathrm{Na}_{2} \mathrm{SO}_{4}(\mathrm{pH} 8.0)$ buffer and centrifuged at $4^{\circ} \mathrm{C}, 15,000 \mathrm{~g}$ for $60 \mathrm{~min}$ (Çakmakçı et al., 2009). Glucose-6-phosphate dehydrogenase (G6PD, EC 1.1.1.49) and 6-phosphogluconate dehydrogenase (6PGD, EC 1.1.1.44) activities were determined according to the method of Minucci et al. (2009). The activities of glutathione reductase (GR; EC 1.8.1.7) and glutathione S-transferase (GST; EC 2.5.1.18) were assayed by the method of Chikezie et al. (2009) and Minucci et al. (2009), respectively. All reactions were initiated by the addition of the enzyme solution. All enzymatic activities were determined spectrophotometrically at $25^{\circ} \mathrm{C}$ using a spectrophotometer Shimadzu 1208 UV (Shimadzu Co., Japan). Protein concentrations were calculated from the measurements of absorbance at $595 \mathrm{~nm}$ according to the method of Song et al. (2015) with bovine serum albumin as a standard.

Determination of antioxidant enzyme activity (SOD, POD, CAT and APX). Plant sample (500 mg dry weight) was homogenized with a mortar and pestle by adding $3 \mathrm{~mL}$ of $50 \mathrm{mM}$ phosphate buffer ( $\mathrm{pH} 7)$. Homogenates were filtered through two layers of Miracloth (Calbiochem, USA) and the filtrate was centrifuged at $15000 \times \mathrm{g}$ for $15 \mathrm{~min}$ at $4^{\circ} \mathrm{C}$. The resulting supernatant was stored at $80^{\circ} \mathrm{C}$. For antioxidant enzyme assays, frozen cell samples were ground to a fine powder under liquid nitrogen and extracted with ice-cold $0.1 \mathrm{mM}$ phosphate buffer, $\mathrm{pH} 7.8$, containing $1 \mathrm{mM}$ ethylenediamine-tetra-acetic acid (EDTA), $1 \mathrm{mM}$ phenylmethanesulphonylfluoride (PMSF) and $0.5 \%$ polyvinylpyrrolidone (PVP). Superoxide dismutase (SOD), peroxidase (POD), catalase (CAT) and ascorbate peroxidase (APX) enzyme activities in the apoplastic fractions were measured spectrophotometrically. The CAT activity was measured by monitoring the decrease in absorbance at $240 \mathrm{~nm}$ in $50 \mathrm{mM}$ phosphate buffer $(\mathrm{pH} 7.5)$ containing $20 \mathrm{mM} \mathrm{H} \mathrm{O}_{2}$. One unit of CAT activity was defined as the amount of enzyme that used $1 \mu \mathrm{mol} \mathrm{H}_{2} \mathrm{O}_{2}$ $\min ^{-1}$. APX activity was determined by following the decrease in A290 (extinction coefficient $2.8 \mathrm{mM}^{-1} \mathrm{~cm}^{-1}$ ) for $1 \mathrm{~min}$ in $1 \mathrm{~mL}$ of a reaction mixture containing $50 \mathrm{mM}$ potassium phosphate buffer $(\mathrm{pH} 7.0), 0.5 \mathrm{mM}$ ascorbic acid, $0.1 \mathrm{mM} \mathrm{H}_{2} \mathrm{O}_{2}$ and $200 \mu \mathrm{l}$ of enzyme extract (Guo et al., 2010). The reaction was started by adding enzyme extract. Correction was done for the low, non-enzymatic oxidation of ascorbic acid by $\mathrm{H}_{2} \mathrm{O}_{2}$. The POD activity was measured by monitoring the increase in absorbance at $470 \mathrm{~nm}$ in $50 \mathrm{mM}$ phosphate buffer ( $\mathrm{pH}$ 5.5) containing $1 \mathrm{mM}$ guaiacol and $0.5 \mathrm{mM} \mathrm{H}_{2} \mathrm{O}_{2}$. One unit of POD activity was defined as the amount of enzyme that caused an increase in absorbance of $0.01 \mathrm{~min}^{-1}$. The SOD activity was estimated by recording the decrease in optical density of nitro-blue tetrazolium dye by the enzyme (Guo et al., 2010). Three milliliters of the reaction mixture contained $2 \mu \mathrm{M}$ riboflavine, $13 \mathrm{mM}$ methionine, $75 \mu \mathrm{M}$ nitroblue tetrazolium chloride, $0.1 \mathrm{mM}$ EDTA, $50 \mathrm{mM}$ phosphate buffer (pH 7.8), $50 \mathrm{mM}$ sodium carbonate and $0.1 \mathrm{~mL}$ of the apoplastic fraction. Reactions were started by adding $60 \mu \mathrm{L}$ from $100 \mu \mathrm{M}$ riboflavine solution and placing the tubes under two $30 \mathrm{~W}$ fluorescent lamps for $15 \mathrm{~min}$. A complete reaction mixture without enzyme, which gave the maximal colour, served as control. Reactions were stopped by switching off the light and putting the tubes into the dark, a non-irradiated complete reaction mixture served as a blank. The absorbance was recorded at $560 \mathrm{~nm}$ and one unit of enzyme, which reduced the absorbance reading to $50 \%$ in comparison with tubes lacking enzyme (Dai, Mumper, 2015).

Total phenolics content (TPC). The amount of TPC in extracts was determined according to the FolinCiocalteu's spectrophotometric 2501 PC (Shimadzu, Japan) procedure (Giannakoula et al., 2012) using gallic acid (GA) as a standard for the calibration curve. The linear reading of the curve was from 0 to $350 \mathrm{mg}$ of GA $\mathrm{mL}^{-1}$. Samples were mixed with $0.25 \mathrm{~N}$ Folin-Ciocalteu reagents and after $3 \mathrm{~min} 0.2 \mathrm{M}$ sodium carbonate solution was added and incubated for $60 \mathrm{~min}$. Results were read at $724 \mathrm{~nm}$ and expressed as $\mathrm{mg}$ of GA equivalents per $\mathrm{g}$ of fresh weight (mg eq $\mathrm{GA} \mathrm{g}^{-1}$ fresh weight).

Trolox equivalent antioxidant capacity (TEAC). The hydrophilic antioxidant capacity was performed by using the $\mathrm{ABTS}^{+}$radical cation assay. In the presence of metmyoglobin and hydrogen peroxide, ABTS is oxidized to the durable radical cation $\mathrm{ABTS}^{+}$measured photometrically at $734 \mathrm{~nm}$. Trolox was used as the standard, and the antioxidant capacity was expressed as trolox equivalent antioxidant capacity (Gündüz, Özdemir, 2014). The results were expressed as $\mu$ mols trolox equivalent in $\mathrm{g}$ fresh weight $\left(\mu \mathrm{mols}\right.$ TE $\mathrm{g}^{-1}$ fresh weight) basis.

Measurement of hydrogen peroxide $\left(\mathrm{H}_{2} \mathrm{O}_{2}\right)$ and malondialdehyde (MDA). The content of $\mathrm{H}_{2} \mathrm{O}_{2}$ was determined according to Sairam and Srivastava (2002) method. The concentration of $\mathrm{H}_{2} \mathrm{O}_{2}$ was estimated by measuring the absorbance of the titanium-hydroperoxide complex and using a standard curve plotted with a known concentration of $\mathrm{H}_{2} \mathrm{O}_{2}$. Oxidative damage to lipids was determined by measuring the content of malondialdehyde (MDA), prepared in 10\% trichloroacetic acid containing $0.65 \%$ 2-thiobarbituric acid (TBA) and heated at $95^{\circ} \mathrm{C}$ for $25 \mathrm{~min}$, and then quickly cooled (Sun et al., 2015). MDA content was calculated by correcting for compounds other than MDA which absorb at $532 \mathrm{~nm}$ by subtracting the absorbance at $532 \mathrm{~nm}$ of a solution containing plant extract incubated without TBA from an identical solution containing TBA.

Plant analysis. Leaf samples were oven-dried at $68^{\circ} \mathrm{C}$ for $48 \mathrm{~h}$ and ground to pass $1 \mathrm{~mm}$. The Kjeldahl method and a Vapodest 10 Rapid Kjeldahl Distillation Unit (G. Gerhardt GmbH, Germany) were used to determine total $\mathrm{N}$ of the strawberry leaves (Bremner, 1996). After extraction methods, tissue P, K, Ca, Fe, Mn, $\mathrm{Zn}$ and $\mathrm{Cu}$ were determined with an inductively coupled plasma spectrophotometer Perkin-Elmer Optima 2100 DV ICP/OES (Perkin-Elmer, USA).

Data collection and statistical analysis. The data were collected both in 2011 and 2012. From each plant, both of the secondary fruits from the primary truss were harvested according to developmental stage. All fruits were harvested at the red stage, which was considered as optimum ripeness. At each harvest, total fresh yield $\left(\mathrm{g} \mathrm{plant}^{-1}\right)$ and number of berries as well as average fresh weight per berry $\left(\mathrm{g} \mathrm{plant}^{-1}\right)$, and titratable acids $(\%)$ were determined. Chlorophyll contents of the top fourth and fifth leaves were measured using a chlorophyll meter SPAD-502 ("Minolta", Japan) which is used to measure leaf greenness of the plants. In addition, we measured the activities of antioxidant enzymes in the leaves of strawberry. Enzyme activities were determined on three samples from each replicate. All data were statistically 
evaluated using analysis of variance (ANOVA), followed by means separation using the Duncan's multiple rangetest at $(p \leq 0.05)$. All calculations were performed with software package STATISTICA 6.0 (StatSoft, USA).

\section{Results}

Water deficit irrigation experiments were conducted on strawberry plants well supplied with water $(100 \%$ water-holding capacity), under mild water stress $(75 \%$ of WHC), moderate water stress $(50 \%$ of WHC) and severe water stress (25\% of WHC). Overall, inoculation with the PGPR strains resulted in a significant increase in growth of all the plants (Table 2). Water deficit, particularly severe water stress $(25 \%$ of WHC), increased berry number per plant and reduced the weight of berry at harvest. The results showed that by increasing water stress, leaf chlorophyll content decreases leading to less photosynthesis, growth and yield. Both the weight of berries and the average berry fresh weight (FW) per plant were reduced by mild water stress (MiWS), moderate water stress (MoWS) and severe water stress (SWS) treatments as compared to full irrigation (FI), even though the increase in berry number per plant was significant (Table 2).

Table 2. Effect of plant growth-promoting rhizobacteria (PGPR) and water deficit treatments on the average number of berries and fresh weight per berry, titratable acidity, chlorophyll contents (SPAD) and yield of strawberry cultivar 'Aromas' as an average of 2011 and 2012

\begin{tabular}{|c|c|c|c|c|c|c|c|c|}
\hline \multirow[t]{2}{*}{ Treatments } & \multirow{2}{*}{$\begin{array}{l}\text { Water } \\
\text { regimes }\end{array}$} & \multirow{2}{*}{$\begin{array}{l}\text { Weight of } \\
\text { berries } \\
\text { g plant }^{-1}\end{array}$} & \multirow{2}{*}{$\begin{array}{c}\text { Number of } \\
\text { berries } \\
\text { per plant }\end{array}$} & \multirow{2}{*}{$\begin{array}{c}\text { Titratable } \\
\text { acidity } \\
\%\end{array}$} & \multirow{2}{*}{$\begin{array}{l}\text { SPAD } \\
\text { value }\end{array}$} & \multicolumn{3}{|c|}{$\begin{array}{l}\text { Yield per plant } \\
\mathrm{g}\end{array}$} \\
\hline & & & & & & 2011 & 2012 & average \\
\hline \multirow[t]{5}{*}{ Control } & FI & $10.48 \mathrm{~cd}^{*}$ & $39.0 \mathrm{ik}$ & $0.84 \mathrm{ab}$ & 39.51 & $344.4 b c$ & $488.3 \mathrm{ac}$ & $416.3 \mathrm{bd}$ \\
\hline & MiWS & $9.35 \mathrm{e}$ & $38.1 \mathrm{jk}$ & 0.81 ae & 40.01 & $296.9 \mathrm{~d}$ & $418.0 \mathrm{df}$ & $357.4 \mathrm{eg}$ \\
\hline & MoWS & $7.10 \mathrm{~g}-\mathrm{j}$ & $42.5 \mathrm{fk}$ & $0.76 \mathrm{ch}$ & 39.61 & $247.3 \mathrm{~g}$ & $360.5 \mathrm{fh}$ & $303.9 \mathrm{hi}$ \\
\hline & SWS & $5.98 \mathrm{~lm}$ & $43.3 \mathrm{ej}$ & $0.71 \mathrm{gh}$ & 39.71 & $187.4 \mathrm{~h}$ & $327.3 \mathrm{~h}$ & $257.3 \mathrm{j}$ \\
\hline & Average & $8.23 \mathrm{c}$ & $40.3 \mathrm{~d}$ & $0.78 \mathrm{bc}$ & $39.7 \mathrm{f}$ & $269.0 \mathrm{~d}$ & $398.5 \mathrm{~d}$ & $333.8 \mathrm{~d}$ \\
\hline \multirow[t]{5}{*}{$\mathrm{RC} 05$} & FI & $11.61 \mathrm{a}$ & $42.0 \mathrm{fk}$ & $0.79 \mathrm{bf}$ & $50.9 \mathrm{a}$ & $410.9 \mathrm{a}$ & $515.8 \mathrm{a}$ & $463.3 \mathrm{a}$ \\
\hline & MiWS & $10.36 \mathrm{~cd}$ & $41.6 \mathrm{gk}$ & $0.76 \mathrm{dh}$ & $48.1 \mathrm{aj}$ & $354.2 \mathrm{~b}$ & $514.7 \mathrm{a}$ & $434.4 \mathrm{ab}$ \\
\hline & MoWS & $7.40 \mathrm{gi}$ & $41.4 \mathrm{~b}$ & $0.74 \mathrm{fh}$ & $48.8 \mathrm{ah}$ & $297.5 \mathrm{~d}$ & $464.7 \mathrm{ad}$ & $381.1 \mathrm{ce}$ \\
\hline & SWS & $6.12 \mathrm{~km}$ & $52.0 \mathrm{~b}$ & $0.71 \mathrm{gh}$ & $47.6 \mathrm{dj}$ & $252.7 \mathrm{fg}$ & $408.3 \mathrm{dg}$ & $330.5 \mathrm{gh}$ \\
\hline & Average & $8.87 \mathrm{ab}$ & $46.2 \mathrm{ac}$ & $0.75 \mathrm{ce}$ & $48.8 \mathrm{ac}$ & $328.8 \mathrm{a}$ & $475.9 \mathrm{a}$ & $402.3 \mathrm{a}$ \\
\hline \multirow[t]{5}{*}{ RC35 } & FI & $11.38 \mathrm{ab}$ & $39.8 \mathrm{ik}$ & $0.82 \mathrm{ac}$ & $50.5 \mathrm{ac}$ & $376.5 \mathrm{~b}$ & $510.3 \mathrm{a}$ & $443.4 \mathrm{ab}$ \\
\hline & MiWS & $9.82 \mathrm{de}$ & $38.5 \mathrm{jk}$ & $0.79 \mathrm{bf}$ & $50.6 \mathrm{ab}$ & $311.4 \mathrm{~cd}$ & 445.7 be & $378.5 \mathrm{ce}$ \\
\hline & MoWS & $6.76 \mathrm{hl}$ & $50.4 \mathrm{bc}$ & $0.77 \mathrm{cg}$ & $49.6 \mathrm{ae}$ & $284.6 \mathrm{df}$ & $396.4 \mathrm{eg}$ & $340.5 \mathrm{eh}$ \\
\hline & SWS & $6.17 \mathrm{~km}$ & $48.5 \mathrm{bd}$ & $0.71 \mathrm{gh}$ & $45.5 \mathrm{jk}$ & $241.8 \mathrm{~g}$ & $352.2 \mathrm{gh}$ & $297.0 \mathrm{hj}$ \\
\hline & Average & $8.53 \mathrm{bc}$ & $44.3 \mathrm{ac}$ & $0.77 \mathrm{bd}$ & $49.1 \mathrm{ab}$ & $303.6 \mathrm{~b}$ & $426.1 \mathrm{bd}$ & $364.9 \mathrm{~b}$ \\
\hline \multirow[t]{5}{*}{ RC77 } & FI & 10.79 bc & $40.3 \mathrm{ik}$ & $0.76 \mathrm{dh}$ & $49.2 \mathrm{ag}$ & $371.5 \mathrm{~b}$ & $500.2 \mathrm{ab}$ & $435.9 \mathrm{ab}$ \\
\hline & MiWS & $10.27 \mathrm{~cd}$ & $37.4 \mathrm{k}$ & $0.76 \mathrm{dh}$ & $47.8 \mathrm{bj}$ & $311.7 \mathrm{~cd}$ & 445.4 be & $378.6 \mathrm{ce}$ \\
\hline & MoWS & $7.47 \mathrm{gh}$ & $47.0 \mathrm{bf}$ & $0.73 \mathrm{fh}$ & $47.4 \mathrm{ek}$ & $288.1 \mathrm{de}$ & $419.7 \mathrm{df}$ & $353.9 \mathrm{eg}$ \\
\hline & SWS & $6.89 \mathrm{hk}$ & $46.0 \mathrm{cg}$ & $0.70 \mathrm{~h}$ & $46.2 \mathrm{hk}$ & $246.4 \mathrm{~g}$ & $398.6 \mathrm{eg}$ & $322.5 \mathrm{gh}$ \\
\hline & Average & $8.86 \mathrm{ab}$ & $42.3 \mathrm{~cd}$ & $0.74 \mathrm{de}$ & $47.6 \mathrm{ce}$ & $304.4 \mathrm{~b}$ & $441.0 \mathrm{ab}$ & $372.7 \mathrm{~b}$ \\
\hline \multirow[t]{5}{*}{$\mathrm{RC} 86$} & FI & $10.37 \mathrm{~cd}$ & $40.5 \mathrm{gk}$ & $0.85 \mathrm{a}$ & $48.6 \mathrm{ah}$ & $258.2 \mathrm{~b}$ & $483.0 \mathrm{ac}$ & $420.7 \mathrm{ac}$ \\
\hline & MiWS & $7.82 \mathrm{fg}$ & $45.5 \mathrm{ch}$ & $0.81 \mathrm{ae}$ & 48.8 ai & $297.3 \mathrm{~d}$ & $427.6 \mathrm{ce}$ & $362.5 \mathrm{eg}$ \\
\hline & MoWS & $6.32 \mathrm{jm}$ & $48.6 \mathrm{bd}$ & $0.77 \mathrm{cg}$ & $46.6 \mathrm{fk}$ & $255.7 \mathrm{eg}$ & $363.9 \mathrm{fh}$ & $309.8 \mathrm{hi}$ \\
\hline & SWS & $5.83 \mathrm{~m}$ & $46.9 \mathrm{bf}$ & $0.74 \mathrm{fh}$ & $48.0 \mathrm{aj}$ & $195.8 \mathrm{~h}$ & $349.5 \mathrm{gh}$ & $272.6 \mathrm{ij}$ \\
\hline & Average & $7.58 \mathrm{~d}$ & $45.5 \mathrm{ac}$ & $0.79 \mathrm{ab}$ & $47.9 \mathrm{bd}$ & $276.8 \mathrm{~cd}$ & $406.0 \mathrm{~cd}$ & $341.4 \mathrm{~cd}$ \\
\hline \multirow[t]{5}{*}{ RC06 } & FI & $10.56 \mathrm{~cd}$ & $39.0 \mathrm{ik}$ & $0.77 \mathrm{cg}$ & $50.4 \mathrm{ad}$ & $358.2 \mathrm{~b}$ & $468.6 \mathrm{ad}$ & $413.4 \mathrm{bd}$ \\
\hline & MiWS & $9.22 \mathrm{e}$ & $40.5 \mathrm{gk}$ & $0.75 \mathrm{eh}$ & 49.4 af & $305.2 \mathrm{~d}$ & 446.3 be & $375.7 \mathrm{df}$ \\
\hline & MoWS & $7.17 \mathrm{gi}$ & $46.0 \mathrm{cg}$ & $0.72 \mathrm{gh}$ & $49.3 \mathrm{ag}$ & $260.8 \mathrm{eg}$ & $405.9 \mathrm{dg}$ & $333.3 \mathrm{fh}$ \\
\hline & SWS & $6.00 \mathrm{~lm}$ & $49.0 \mathrm{bd}$ & $0.70 \mathrm{~h}$ & $49.0 \mathrm{ah}$ & $205.5 \mathrm{~h}$ & $396.3 \mathrm{eg}$ & $300.9 \mathrm{hi}$ \\
\hline & Average & $8.24 \mathrm{c}$ & $44.0 \mathrm{bd}$ & $0.73 \mathrm{e}$ & $49.5 \mathrm{a}$ & $282.4 \mathrm{~cd}$ & $429.3 \mathrm{bc}$ & $365.9 \mathrm{bc}$ \\
\hline \multirow[t]{5}{*}{$29 / 2$} & FI & $9.92 \mathrm{de}$ & $43.9 \mathrm{di}$ & $0.79 \mathrm{bf}$ & $48.5 \mathrm{ah}$ & $370.1 \mathrm{~b}$ & $500.3 \mathrm{ab}$ & $435.2 \mathrm{ab}$ \\
\hline & MiWS & $7.70 \mathrm{fg}$ & 47.9 be & $0.75 \mathrm{dh}$ & $47.5 \mathrm{ej}$ & $308.8 \mathrm{~d}$ & 441.4 be & $375.1 \mathrm{df}$ \\
\hline & MoWS & $6.66 \mathrm{il}$ & $50.0 \mathrm{bc}$ & $0.73 \mathrm{fh}$ & $45.6 \mathrm{ik}$ & $261.8 \mathrm{eg}$ & $411.2 \mathrm{dg}$ & $336.5 \mathrm{eh}$ \\
\hline & SWS & $5.57 \mathrm{~m}$ & $49.4 \mathrm{bc}$ & $0.70 \mathrm{~h}$ & $44.7 \mathrm{k}$ & $203.0 \mathrm{~h}$ & $353.7 \mathrm{gh}$ & $278.3 \mathrm{ij}$ \\
\hline & Average & $7.46 \mathrm{~d}$ & $48.2 \mathrm{a}$ & $0.74 \mathrm{de}$ & $46.5 \mathrm{e}$ & $285.9 \mathrm{c}$ & $426.6 \mathrm{bd}$ & $356.3 \mathrm{bc}$ \\
\hline \multirow[t]{5}{*}{ RC9 } & FI & $11.70 \mathrm{a}$ & $42.5 \mathrm{fk}$ & $0.85 \mathrm{a}$ & $50.9 \mathrm{a}$ & $433.0 \mathrm{a}$ & $491.0 \mathrm{ac}$ & $462.0 \mathrm{a}$ \\
\hline & MiWS & $10.35 \mathrm{~cd}$ & $42.5 \mathrm{fk}$ & $0.84 \mathrm{ab}$ & $47.7 \mathrm{cj}$ & $365.5 \mathrm{~b}$ & $518.3 \mathrm{a}$ & $441.9 \mathrm{ab}$ \\
\hline & MoWS & $8.32 \mathrm{f}$ & $45.5 \mathrm{ch}$ & 0.81 ae & $44.7 \mathrm{k}$ & $312.5 \mathrm{~cd}$ & 446.5 be & 379.5 ce \\
\hline & SWS & $5.58 \mathrm{~m}$ & $56.5 \mathrm{a}$ & $0.77 \mathrm{cg}$ & $46.4 \mathrm{gk}$ & $247.6 \mathrm{~g}$ & $409.5 \mathrm{dg}$ & $328.5 \mathrm{gh}$ \\
\hline & Average & $8.99 \mathrm{a}$ & $46.9 \mathrm{ab}$ & $0.82 \mathrm{a}$ & $47.4 \mathrm{de}$ & $339.7 \mathrm{a}$ & $466.3 \mathrm{a}$ & $403.0 \mathrm{a}$ \\
\hline \multirow[t]{4}{*}{ Average } & FI & $10.85 \mathrm{a}$ & $40.0 \mathrm{~b}$ & $0.81 \mathrm{a}$ & $48.5 \mathrm{a}$ & $377.9 \mathrm{a}$ & $494.7 \mathrm{a}$ & $436.3 \mathrm{a}$ \\
\hline & MiWS & $9.36 \mathrm{~b}$ & $41.5 \mathrm{~b}$ & $0.78 \mathrm{~b}$ & $47.4 \mathrm{~b}$ & $318.9 \mathrm{~b}$ & $457.2 \mathrm{~b}$ & $388.0 \mathrm{~b}$ \\
\hline & MoWS & $7.15 \mathrm{c}$ & $47.9 \mathrm{a}$ & $0.75 \mathrm{c}$ & $46.4 \mathrm{c}$ & $276.0 \mathrm{c}$ & $408.6 \mathrm{c}$ & $342.3 \mathrm{c}$ \\
\hline & SWS & $6.02 \mathrm{~d}$ & $49.4 \mathrm{a}$ & $0.72 \mathrm{~d}$ & $45.9 \mathrm{c}$ & $222.5 \mathrm{~d}$ & $374.4 \mathrm{~d}$ & $298.5 \mathrm{~d}$ \\
\hline
\end{tabular}

Note. FI - full irrigation (100\% water-holding capacity), MiWS - mild water stress (75\% of WHC), MoWS - moderate water stress $\left(50 \%\right.$ of WHC), SWS - severe water stress $\left(25 \%\right.$ of WHC); ${ }^{*}$ - values followed by different lower-case letters in a column (each section separately) were significantly different $(P \leq 0.05)$. 
Except for RC86, all strains improved the plant growth and increased the yield. The water-stressed plants inoculated with the effective PGPR recorded improved plant growth in terms of number of berries per plant, chlorophyll contents and berry yield in comparison to the un-inoculated, water-stressed plants (Table 2). On average of both years and four water regimes, inoculation of PGPR increased the berry yield, except RC86. All the strains enhanced (up to 17.1-24.7\%) chlorophyll contents as compared to the control. Of these seven bacteria, higher fresh berry weight, and berry yield were recorded in plants applied with RC05, RC9, RC35 and RC77. Thus, on average in four water regimes, in 2011, inoculation with RC05, RC35, RC77, RC86, RC06, 29/2 and RC9 increased berry yields over control by 22.2 , $12.9,13.2,2.9,5.0,6.3$ and $26.3 \%$, respectively. In the growth season of 2012 similar increases were obtained (Table 2). Thus, on average of both years and four water regimes, inoculation with $\mathrm{RC} 05, \mathrm{RC} 35, \mathrm{RC} 77, \mathrm{RC} 86$, RC06, 29/2 and RC9 increased the berry yield by 20.5, $9.3,11.7,2.3,9.6,6.7$ and $20.7 \%$, respectively, compared with the control.

The data revealed that drought stress applied at $25 \%$ of WHC had the most negative effect on the fresh berry weight and yield of strawberry cv. 'Aromas'. However, inoculation with ACC deaminase-containing, IAA-producing, $\mathrm{N}_{2}$-fixing, $\mathrm{P}$-solubilizing PGPR reduced the effects of drought stress applied owing to low soil moisture and, in most of the cases, significantly increased the fresh weight and yield compared with their respective uninoculated control. On average of both years, maximum increase in fresh berry yield was recorded in the case of strawberry plants inoculated with RC05 under moderate and severe drought stress applied at $50 \%$ and $25 \% \mathrm{WHC}$, and it was $25.4 \%$ and $28.4 \%$ higher than the respective uninoculated control. At $100 \%$ of WHC, inoculation with RC 05 caused maximum increase in the yield of berry that was $11.3 \%$ higher than the respective uninoculated control.

Drought stress decreased mineral uptake and the yield of strawberry cultivar 'Aromas', and generally, inoculation of the multi-trait bacteria under drought stress significantly improved the N, P, K, Ca, Fe, Mn, $\mathrm{Zn}$ and $\mathrm{Cu}$ uptake, but mineral uptake responses were strain-specific (Table 3). Three of the PGPR strains (RC35, RC86 and 29/2) did not change the N content of the strawberry plants. On the other hand, the other four strains significantly increased $\mathrm{N}$ concentrations. The maximum $\mathrm{P}$ and $\mathrm{K}$ concentration in the strawberry leaves was found after RC77 treatment, followed by RC05, RC9 and RC35 treatments. Except for RC35, the bacterial inoculation significantly increased the $\mathrm{Ca}$ concentration in strawberry, and strains RC05, RC77, RC86, RC06 and RC9 increased the Mn concentration (Table 3). P. fluorescens RC77 inoculants significantly increased the Fe content, while RC05, RC77, RC86 and $\mathrm{RC} 35$ inoculation increased the $\mathrm{Zn}$ concentration in the leaves of strawberry.

Table 3. Effect of plant growth-promoting rhizobacteria (PGPR) and water deficit treatments on macro- and micronutrient concentrations in strawberry leaves

\begin{tabular}{|c|c|c|c|c|c|c|c|c|c|}
\hline \multirow{2}{*}{ Treatments $^{1}$} & \multirow{2}{*}{$\begin{array}{l}\text { Water } \\
\text { regimes }^{1}\end{array}$} & \multirow{2}{*}{$\begin{array}{l}\mathrm{N} \\
\%\end{array}$} & \multicolumn{3}{|c|}{ Macro-nutrients $\mathrm{g} \mathrm{kg}^{-1} \mathrm{DW}$} & \multicolumn{4}{|c|}{ Micro-nutrients $\mathrm{mg} \mathrm{kg}^{-1} \mathrm{DW}$} \\
\hline & & & $\mathrm{P}$ & $\mathrm{K}$ & $\mathrm{Ca}$ & $\mathrm{Fe}$ & $\mathrm{Mn}$ & $\mathrm{Zn}$ & $\mathrm{Cu}$ \\
\hline 1 & 2 & 3 & 4 & 5 & 6 & 7 & 8 & 9 & 10 \\
\hline \multirow[t]{5}{*}{ Control } & FI & $2.84 \mathrm{cf}^{2}$ & $2.42 \mathrm{~d}-\mathrm{f}$ & $25.42 \mathrm{ik}$ & $23.71 \mathrm{ij}$ & 20.15 af & $15.46 \mathrm{gi}$ & $13.26 \mathrm{~h}$ & $6.24 \mathrm{bg}$ \\
\hline & MiWS & $2.80 \mathrm{df}$ & $2.31 \mathrm{f}$ & $25.10 \mathrm{jk}$ & $23.11 \mathrm{j}$ & $18.52 \mathrm{eh}$ & $13.97 \mathrm{hj}$ & $13.85 \mathrm{dh}$ & $5.47 \mathrm{~g}$ \\
\hline & MoWS & $2.81 \mathrm{cf}$ & $2.31 \mathrm{f}$ & $25.70 \mathrm{hk}$ & $23.69 \mathrm{ij}$ & $18.13 \mathrm{fh}$ & $13.29 \mathrm{j}$ & $12.74 \mathrm{~h}$ & $5.47 \mathrm{~g}$ \\
\hline & SWS & $2.78 \mathrm{df}$ & $2.38 \mathrm{~d}-\mathrm{f}$ & $24.99 \mathrm{k}$ & $23.00 \mathrm{j}$ & $17.15 \mathrm{~h}$ & $13.333 \mathrm{j}$ & $12.69 \mathrm{~h}$ & $5.46 \mathrm{~g}$ \\
\hline & Average & $2.81 \mathrm{c}$ & $2.35 \mathrm{c}$ & $25.30 \mathrm{~d}$ & $23.39 \mathrm{c}$ & $18.49 \mathrm{bc}$ & $14.01 \mathrm{~b}$ & $13.13 \mathrm{c}$ & $5.66 \mathrm{~d}$ \\
\hline \multirow[t]{5}{*}{$\mathrm{RC} 05$} & FI & $3.26 \mathrm{a}$ & $2.51 \mathrm{af}$ & $33.54 \mathrm{a}$ & $33.43 \mathrm{ab}$ & $21.65 \mathrm{a}$ & 17.93 be & $15.27 \mathrm{ad}$ & $6.62 \mathrm{ae}$ \\
\hline & MiWS & $3.10 \mathrm{ad}$ & $2.61 \mathrm{ae}$ & 30.27 af & $31.84 \mathrm{bd}$ & $18.10 \mathrm{fh}$ & $17.37 \mathrm{cf}$ & $15.74 \mathrm{ab}$ & $6.44 \mathrm{ae}$ \\
\hline & MoWS & 2.96 af & $2.40 \mathrm{df}$ & $28.83 \mathrm{dh}$ & $28.74 \mathrm{ef}$ & $19.59 \mathrm{ag}$ & $15.41 \mathrm{gi}$ & $15.88 \mathrm{ab}$ & $6.09 \mathrm{eg}$ \\
\hline & SWS & $2.82 \mathrm{cf}$ & $2.59 \mathrm{af}$ & $27.97 \mathrm{ek}$ & $25.89 \mathrm{fj}$ & $18.66 \mathrm{dh}$ & $13.88 \mathrm{hj}$ & $14.57 \mathrm{bf}$ & $6.02 \mathrm{dg}$ \\
\hline & Average & $3.03 \mathrm{a}$ & $2.53 \mathrm{ab}$ & $30.15 \mathrm{ab}$ & $29.97 \mathrm{a}$ & $19.50 \mathrm{ab}$ & $16.15 \mathrm{a}$ & $15.36 \mathrm{a}$ & $6.29 \mathrm{~b}$ \\
\hline \multirow[t]{5}{*}{ RC35 } & FI & $3.15 \mathrm{ac}$ & $2.75 \mathrm{ab}$ & $29.76 \mathrm{bg}$ & 29.56 ce & $20.89 \mathrm{ad}$ & $17.39 \mathrm{cf}$ & $15.46 \mathrm{ac}$ & $6.29 \mathrm{bf}$ \\
\hline & MiWS & $2.83 \mathrm{cf}$ & $2.32 \mathrm{ef}$ & $29.75 \mathrm{bg}$ & $29.56 \mathrm{ce}$ & $19.22 \mathrm{ch}$ & $15.66 \mathrm{fh}$ & 14.72 be & $6.02 \mathrm{dg}$ \\
\hline & MoWS & $2.89 \mathrm{bf}$ & $2.36 \mathrm{df}$ & $28.47 \mathrm{di}$ & $24.14 \mathrm{hj}$ & 20.09 af & $14.20 \mathrm{hj}$ & $13.26 \mathrm{eh}$ & $5.47 \mathrm{~g}$ \\
\hline & SWS & $2.83 \mathrm{cf}$ & $2.62 \mathrm{a}-\mathrm{d}$ & $27.05 \mathrm{fk}$ & $23.15 \mathrm{j}$ & $18.26 \mathrm{eh}$ & $13.62 \mathrm{ij}$ & $13.26 \mathrm{eh}$ & $5.46 \mathrm{~g}$ \\
\hline & Average & $2.92 \mathrm{ac}$ & $2.51 \mathrm{ab}$ & $29.06 \mathrm{bc}$ & $25.87 \mathrm{bc}$ & $19.61 \mathrm{ab}$ & $15.22 \mathrm{~b}$ & $14.11 \mathrm{~b}$ & $5.81 \mathrm{~cd}$ \\
\hline \multirow[t]{5}{*}{ RC77 } & FI & $3.25 \mathrm{a}$ & $2.76 \mathrm{a}$ & $33.18 \mathrm{a}$ & $31.83 \mathrm{bd}$ & 20.24 af & 18.01 be & $15.90 \mathrm{ab}$ & $6.76 \mathrm{ad}$ \\
\hline & MiWS & 3.07 ae & $2.76 \mathrm{a}$ & $32.52 \mathrm{ab}$ & $33.44 \mathrm{ab}$ & $20.87 \mathrm{ad}$ & $19.16 \mathrm{ad}$ & $14.07 \mathrm{ch}$ & 6.51 ae \\
\hline & MoWS & $2.95 \mathrm{af}$ & $2.52 \mathrm{a}-\mathrm{f}$ & $32.18 \mathrm{ac}$ & $24.59 \mathrm{gj}$ & $20.45 \mathrm{ae}$ & $14.09 \mathrm{hj}$ & $15.90 \mathrm{ab}$ & $5.86 \mathrm{eg}$ \\
\hline & SWS & $2.84 \mathrm{cf}$ & $2.44 \mathrm{~d}-\mathrm{f}$ & $29.29 \mathrm{bg}$ & $24.77 \mathrm{gj}$ & $18.42 \mathrm{eh}$ & $14.19 \mathrm{hj}$ & $14.51 \mathrm{bg}$ & $5.57 \mathrm{fg}$ \\
\hline & Average & $3.02 \mathrm{ab}$ & $2.62 \mathrm{a}$ & $31.80 \mathrm{a}$ & $28.66 \mathrm{ab}$ & $19.99 \mathrm{a}$ & $16.36 \mathrm{a}$ & $15.23 \mathrm{a}$ & $6.17 \mathrm{bc}$ \\
\hline \multirow[t]{5}{*}{ RC86 } & FI & 3.04 af & $2.74 \mathrm{a}-\mathrm{c}$ & $31.58 \mathrm{ad}$ & $34.55 \mathrm{ab}$ & $21.61 \mathrm{ab}$ & $20.36 \mathrm{a}$ & $16.48 \mathrm{a}$ & $6.20 \mathrm{bg}$ \\
\hline & MiWS & $2.86 \mathrm{bf}$ & $2.40 \mathrm{~d}-\mathrm{f}$ & $28.12 \mathrm{ek}$ & $32.59 \mathrm{~b}$ & $19.25 \mathrm{ch}$ & $19.20 \mathrm{ac}$ & 14.72 be & $5.54 \mathrm{fg}$ \\
\hline & MoWS & $2.77 \mathrm{df}$ & $2.35 \mathrm{~d}-\mathrm{f}$ & $24.78 \mathrm{k}$ & $23.26 \mathrm{j}$ & $17.33 \mathrm{gh}$ & $13.24 \mathrm{j}$ & $14.47 \mathrm{bg}$ & $5.45 \mathrm{~g}$ \\
\hline & SWS & $2.72 \mathrm{f}$ & $2.44 \mathrm{~d}-\mathrm{f}$ & $25.31 \mathrm{ik}$ & $23.97 \mathrm{ij}$ & $17.15 \mathrm{~h}$ & $14.12 \mathrm{hj}$ & $14.15 \mathrm{ch}$ & $5.46 \mathrm{~g}$ \\
\hline & Average & $2.85 \mathrm{bc}$ & $2.48 \mathrm{a}-\mathrm{c}$ & $27.45 \mathrm{c}$ & $28.59 \mathrm{ab}$ & $18.84 \mathrm{ac}$ & $16.73 \mathrm{a}$ & $14.95 \mathrm{a}$ & $5.66 \mathrm{~d}$ \\
\hline \multirow{5}{*}{ RC06 } & FI & $3.11 \mathrm{ad}$ & $2.55 \mathrm{af}$ & $31.27 \mathrm{ae}$ & $36.29 \mathrm{a}$ & $19.40 \mathrm{bh}$ & $19.99 \mathrm{a}$ & $14.10 \mathrm{ch}$ & $7.17 \mathrm{a}$ \\
\hline & MiWS & $3.00 \mathrm{af}$ & $2.41 \mathrm{df}$ & $28.42 \mathrm{dj}$ & $36.21 \mathrm{a}$ & $21.67 \mathrm{a}$ & $19.41 \mathrm{ab}$ & $12.70 \mathrm{~h}$ & $6.95 \mathrm{ab}$ \\
\hline & MoWS & $2.93 \mathrm{af}$ & $2.45 \mathrm{cf}$ & $27.07 \mathrm{fk}$ & $27.54 \mathrm{eg}$ & $17.96 \mathrm{fh}$ & $14.76 \mathrm{gj}$ & $12.68 \mathrm{~h}$ & $6.15 \mathrm{cg}$ \\
\hline & SWS & 2.93 af & $2.60 \mathrm{af}$ & $26.59 \mathrm{gk}$ & $25.50 \mathrm{gj}$ & $19.52 \mathrm{ag}$ & $13.67 \mathrm{ij}$ & $12.96 \mathrm{gh}$ & $5.58 \mathrm{fg}$ \\
\hline & Average & $2.99 \mathrm{ab}$ & $2.50 \mathrm{ac}$ & $28.34 \mathrm{bc}$ & $31.38 \mathrm{a}$ & $19.64 \mathrm{ab}$ & $16.96 \mathrm{a}$ & $13.11 \mathrm{c}$ & $6.71 \mathrm{a}$ \\
\hline \multirow[t]{2}{*}{$29 / 2$} & FI & $3.11 \mathrm{ad}$ & $2.30 \mathrm{f}$ & 30.27 af & $28.92 \mathrm{cf}$ & $18.66 \mathrm{dh}$ & $15.64 \mathrm{fh}$ & $12.65 \mathrm{~h}$ & $7.20 \mathrm{a}$ \\
\hline & MiWS & $2.90 \mathrm{bf}$ & $2.38 \mathrm{df}$ & $29.11 \mathrm{cg}$ & $25.37 \mathrm{gj}$ & $17.12 \mathrm{~h}$ & $13.89 \mathrm{hj}$ & $12.87 \mathrm{~h}$ & $6.87 \mathrm{ac}$ \\
\hline
\end{tabular}


Table 3 continued

\begin{tabular}{cccccccccc}
\hline 1 & 2 & 3 & 4 & 5 & 6 & 7 & 7 & 8 & 10 \\
\hline & MoWS & $2.76 \mathrm{ef}$ & $2.47 \mathrm{af}$ & $28.54 \mathrm{di}$ & $25.93 \mathrm{fj}$ & $18.04 \mathrm{fh}$ & $14.20 \mathrm{hj}$ & $12.77 \mathrm{~h}$ & $6.61 \mathrm{ae}$ \\
& SWS & $2.73 \mathrm{ef}$ & $2.40 \mathrm{df}$ & $26.89 \mathrm{fk}$ & $24.87 \mathrm{gj}$ & $17.69 \mathrm{gh}$ & $13.62 \mathrm{ij}$ & $13.27 \mathrm{eh}$ & $6.12 \mathrm{cg}$ \\
& Average & $2.88 \mathrm{ac}$ & $2.39 \mathrm{bc}$ & $28.70 \mathrm{bc}$ & $26.28 \mathrm{~b}$ & $17.88 \mathrm{c}$ & $14.34 \mathrm{~b}$ & $12.89 \mathrm{c}$ & $6.70 \mathrm{a}$ \\
\hline RC9 & FI & $3.26 \mathrm{a}$ & $2.73 \mathrm{ac}$ & $32.49 \mathrm{ab}$ & $27.20 \mathrm{eh}$ & $21.28 \mathrm{ac}$ & $16.53 \mathrm{dg}$ & $13.18 \mathrm{eh}$ & $6.24 \mathrm{bg}$ \\
& MiWS & $3.19 \mathrm{ab}$ & $2.36 \mathrm{df}$ & $29.09 \mathrm{cg}$ & $29.24 \mathrm{ce}$ & $18.10 \mathrm{fh}$ & $17.77 \mathrm{be}$ & $12.87 \mathrm{~h}$ & $6.12 \mathrm{cg}$ \\
& MoWS & $2.91 \mathrm{bf}$ & $2.51 \mathrm{af}$ & $29.27 \mathrm{bg}$ & $26.65 \mathrm{ei}$ & $19.34 \mathrm{ch}$ & $16.20 \mathrm{dg}$ & $12.67 \mathrm{~h}$ & $5.57 \mathrm{fg}$ \\
& SWS & $2.71 \mathrm{f}$ & $2.46 \mathrm{bf}$ & $26.93 \mathrm{fk}$ & $24.17 \mathrm{hj}$ & $18.42 \mathrm{eh}$ & $14.69 \mathrm{gj}$ & $12.69 \mathrm{~h}$ & $5.46 \mathrm{~g}$ \\
& Average & $3.02 \mathrm{ab}$ & $2.52 \mathrm{ab}$ & $29.45 \mathrm{~b}$ & $26.82 \mathrm{~b}$ & $19.28 \mathrm{ab}$ & $16.30 \mathrm{a}$ & $13.00 \mathrm{c}$ & $5.85 \mathrm{~cd}$ \\
\hline Average & FI & $3.13 \mathrm{a}$ & $2.59 \mathrm{a}$ & $30.94 \mathrm{a}$ & $30.69 \mathrm{a}$ & $20.49 \mathrm{a}$ & $17.66 \mathrm{a}$ & $14.54 \mathrm{a}$ & $6.59 \mathrm{a}$ \\
& MiWS & $2.97 \mathrm{~b}$ & $2.44 \mathrm{~b}$ & $29.05 \mathrm{~b}$ & $29.81 \mathrm{a}$ & $19.11 \mathrm{ab}$ & $17.05 \mathrm{a}$ & $14.01 \mathrm{ab}$ & $6.24 \mathrm{ab}$ \\
& MoWS & $2.87 \mathrm{c}$ & $2.42 \mathrm{~b}$ & $28.11 \mathrm{c}$ & $25.57 \mathrm{~b}$ & $18.87 \mathrm{bc}$ & $14.42 \mathrm{~b}$ & $13.83 \mathrm{ab}$ & $5.83 \mathrm{bc}$ \\
& SWS & $2.79 \mathrm{~d}$ & $2.49 \mathrm{~b}$ & $26.88 \mathrm{~d}$ & $24.42 \mathrm{~b}$ & $18.16 \mathrm{c}$ & $13.89 \mathrm{~b}$ & $13.51 \mathrm{~b}$ & $5.64 \mathrm{c}$ \\
\hline
\end{tabular}

Note. ${ }^{1}$ - bacterial strains and water regimes are explained in Table 1 and under Table 2; DW - dry weight; ${ }^{2}-$ values followed by different lower-case letters in a column (each section separately) were significantly different $(P \leq 0.05)$.

Various enzyme activities, total phenolic and trolox equivalent antioxidant capacity were positively influenced by the RC05, TC35, RC77, 29/2 and RC9

treatments, and were significantly higher than in the control plants under the stress conditions (Fig. 1).
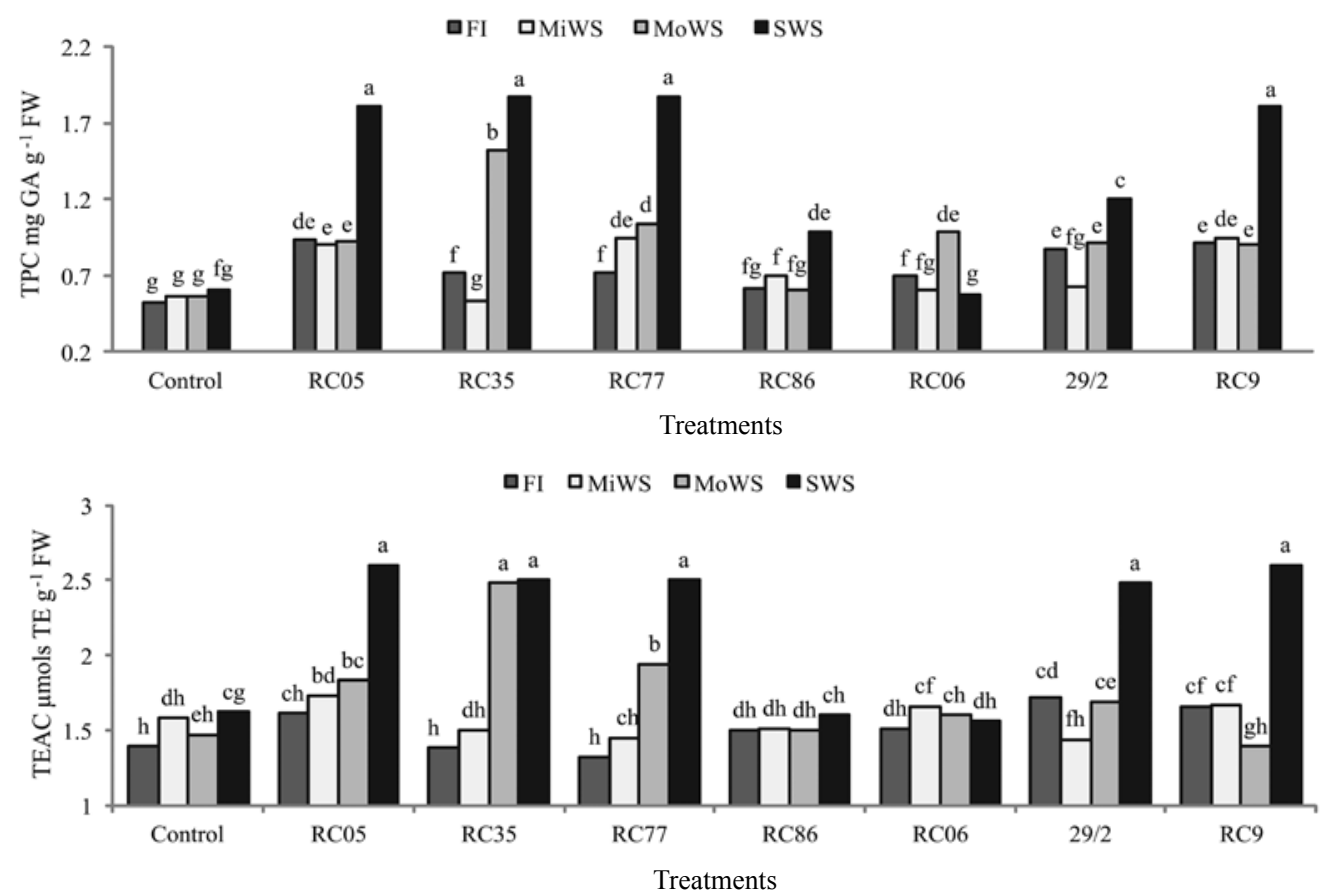

Note. Values with different letters are significantly different at $p \leq 0.05$ (Duncan's test); FW - fresh weight; FI - full irrigation, MiWS - mild water stress, MoWS - moderate water stress, SWS - severe water stress.

Figure 1. Effect of rhizobacterial inoculations on the total phenolics content (TPC) and trolox equivalent antioxidant capacity (TEAC) of strawberry leaves under different irrigation regimes

Under drought stress, there was a significant increase in enzyme activity in both inoculated and uninoculated treatments. In general, enzyme activity in the uninoculated plants was lower than that in inoculated plants (Table 4). GR, CAT, POD, SOD and APX activities were greatest with the application of RC06, whereas the highest levels of GST activity were determined in treatments with RC77. Except for RC35, the bacterial inoculation significantly increased GST; RC06, RC08, RC77, RC86 and 29/2 strains increased GR. Of the bacterial inoculants, maximum CAT and POD in strawberry were measured in the $\mathrm{RC} 06$ followed by $\mathrm{RC} 77, \mathrm{RC} 05$ and $\mathrm{RC} 9$ treatments. In the case of increasing enzyme activities, RC06 and RC77 were the most effective, followed by RC05 and RC9.
The diminishing water supply caused a gradual decrease in the plant growth, accompanied by the increasing concentrations of drought stress markers (MDA and $\mathrm{H}_{2} \mathrm{O}_{2}$ content) in strawberry (Fig. 2). The MDA content was measured to determine the extent of lipid peroxidation. The oxidative damage to lipids increased as a consequence of drought as measured by the MDA content. After drought treatment, gradual increases of $\mathrm{H}_{2} \mathrm{O}_{2}$ and MDA contents were observed in all treatments. The MDA content was higher in control plants at all the stress levels. The highest MDA content under severe drought stress $(25 \%$ of WHC) was observed in the control plants followed by RC86. As the intensity of drought increased, both $\mathrm{H}_{2} \mathrm{O}_{2}$ and MDA levels increased. Compared to well-watered plants, at $25 \%$ of RWC, $\mathrm{H}_{2} \mathrm{O}_{2}$ levels were increased by $74.8 \%$, 
Table 4. Effect of plant growth-promoting rhizobacteria (PGPR) and water deficit treatments on the activities of the antioxidant enzymes (GR, GST, CAT, POD, SOD and APX) and the pentose phosphate oxidative cycle enzymes (G6PD and 6PGD) in the leaves of strawberry cultivar 'Aromas'

\begin{tabular}{|c|c|c|c|c|c|c|c|c|c|}
\hline \multirow{2}{*}{ Treatments $^{1}$} & \multirow{2}{*}{$\begin{array}{c}\text { Water } \\
\text { regimes }^{1}\end{array}$} & GR & GST & G6PD & 6GPD & CAT & POD & SOD & APX \\
\hline & & \multicolumn{4}{|c|}{ units $\mathrm{mg}^{-1}$ protein } & \multicolumn{4}{|c|}{ units $\mathrm{g}^{-1} \mathrm{FW}$} \\
\hline \multirow[t]{5}{*}{ Control } & FI & $2.00 \mathrm{j}^{2}$ & $0.93 \mathrm{~h}$ & $1.50 \mathrm{f}$ & $3.60 \mathrm{fg}$ & $373 \mathrm{f}$ & $27.1 \mathrm{~h}$ & $319 \mathrm{f}$ & $2.60 \mathrm{~g}$ \\
\hline & MiWS & $2.01 \mathrm{j}$ & $1.07 \mathrm{gh}$ & $2.40 \mathrm{df}$ & $3.94 \mathrm{eg}$ & $448 \mathrm{e}$ & $31.0 \mathrm{~h}$ & $336 \mathrm{f}$ & $3.20 \mathrm{~g}$ \\
\hline & MoWS & $3.00 \mathrm{ej}$ & $1.28 \mathrm{eh}$ & $2.07 \mathrm{ef}$ & $5.68 \mathrm{dg}$ & 490 ce & $36.2 \mathrm{~g}$ & 487 a-c & $10.36 \mathrm{e}$ \\
\hline & SWS & $2.79 \mathrm{fj}$ & $1.21 \mathrm{fh}$ & 2.04 ef & $5.94 \mathrm{df}$ & $516 \mathrm{~cd}$ & $46.2 \mathrm{de}$ & $515 \mathrm{a}$ & $19.55 \mathrm{~b}$ \\
\hline & Average & $2.45 \mathrm{e}$ & $1.12 \mathrm{~d}$ & $2.00 \mathrm{de}$ & $4.79 \mathrm{~d}$ & $457 \mathrm{c}$ & $35.1 \mathrm{c}$ & $414 \mathrm{bc}$ & $8.93 \mathrm{c}$ \\
\hline \multirow[t]{5}{*}{$\mathrm{RC} 05$} & FI & $2.56 \mathrm{gj}$ & $1.73 \mathrm{cg}$ & $1.78 \mathrm{f}$ & $5.88 \mathrm{df}$ & $566 \mathrm{bc}$ & $46.8 \mathrm{de}$ & $431 \mathrm{de}$ & $14.92 \mathrm{~cd}$ \\
\hline & MiWS & $3.00 \mathrm{ej}$ & $1.89 \mathrm{cf}$ & $2.41 \mathrm{df}$ & $6.00 \mathrm{df}$ & $583 \mathrm{ab}$ & $48.3 \mathrm{de}$ & 449 ce & $15.14 \mathrm{~cd}$ \\
\hline & MoWS & $2.79 \mathrm{fj}$ & $1.93 \mathrm{ce}$ & $2.74 \mathrm{cf}$ & $6.61 \mathrm{bd}$ & $589 \mathrm{ab}$ & $50.1 \mathrm{~d}$ & 463 be & $20.68 \mathrm{ab}$ \\
\hline & SWS & $2.87 \mathrm{ej}$ & $1.95 \mathrm{ce}$ & $3.62 \mathrm{bd}$ & $7.09 \mathrm{ad}$ & 496 ce & $62.6 \mathrm{ac}$ & $522 \mathrm{a}$ & $22.27 \mathrm{a}$ \\
\hline & Average & $2.80 \mathrm{de}$ & $1.91 \mathrm{~b}$ & $2.64 \mathrm{c}$ & $6.39 \mathrm{bc}$ & $558 \mathrm{ab}$ & $51.94 \mathrm{ab}$ & $466 \mathrm{a}$ & $18.25 \mathrm{a}$ \\
\hline \multirow[t]{5}{*}{$\mathrm{RC} 35$} & FI & $2.13 \mathrm{ij}$ & $1.10 \mathrm{gh}$ & $1.58 \mathrm{f}$ & $3.83 \mathrm{eg}$ & $319 \mathrm{f}$ & $29.4 \mathrm{~h}$ & $321 \mathrm{~h}$ & $2.75 \mathrm{~g}$ \\
\hline & MiWS & $2.15 \mathrm{ij}$ & $0.92 \mathrm{~h}$ & $2.52 \mathrm{df}$ & $3.48 \mathrm{~g}$ & $369 \mathrm{f}$ & $29.2 \mathrm{~h}$ & $343 \mathrm{f}$ & $3.10 \mathrm{~g}$ \\
\hline & MoWS & $2.73 \mathrm{fj}$ & $1.06 \mathrm{gh}$ & $4.54 \mathrm{ab}$ & $6.48 \mathrm{bd}$ & $373 \mathrm{f}$ & $29.6 \mathrm{~h}$ & $366 \mathrm{f}$ & $9.48 \mathrm{e}$ \\
\hline & SWS & $4.17 \mathrm{ae}$ & $1.57 \mathrm{ch}$ & $4.57 \mathrm{ab}$ & $8.47 \mathrm{ac}$ & $509 \mathrm{~cd}$ & $61.1 \mathrm{bc}$ & $499 \mathrm{ab}$ & $19.57 \mathrm{~b}$ \\
\hline & Average & $2.80 \mathrm{de}$ & $1.16 \mathrm{~d}$ & $3.30 \mathrm{~b}$ & $5.57 \mathrm{~cd}$ & $392 \mathrm{~d}$ & $27.3 \mathrm{c}$ & $382 \mathrm{c}$ & $8.72 \mathrm{c}$ \\
\hline \multirow[t]{5}{*}{ RC77 } & FI & $3.16 \mathrm{cj}$ & $1.98 \mathrm{~cd}$ & $3.75 \mathrm{bc}$ & $7.29 \mathrm{ad}$ & $594 \mathrm{ab}$ & $53.2 \mathrm{~d}$ & $436 \mathrm{de}$ & $14.96 \mathrm{~cd}$ \\
\hline & MiWS & $4.41 \mathrm{ac}$ & $2.82 \mathrm{a}$ & $5.80 \mathrm{a}$ & $8.88 \mathrm{ab}$ & $594 \mathrm{ab}$ & $66.7 \mathrm{a}$ & $431 \mathrm{de}$ & $16.06 \mathrm{c}$ \\
\hline & MoWS & $4.60 \mathrm{ab}$ & $2.65 \mathrm{ab}$ & $5.64 \mathrm{a}$ & $8.83 \mathrm{ab}$ & $589 \mathrm{ab}$ & $48.3 \mathrm{de}$ & 448 c-e & $20.74 \mathrm{ab}$ \\
\hline & SWS & $5.10 \mathrm{a}$ & $2.94 \mathrm{a}$ & $5.80 \mathrm{a}$ & $9.16 \mathrm{a}$ & 496 c-e & $40.1 \mathrm{fg}$ & 481 a-d & $20.90 \mathrm{ab}$ \\
\hline & Average & $4.32 \mathrm{ab}$ & $2.60 \mathrm{a}$ & $5.25 \mathrm{a}$ & $8.54 \mathrm{a}$ & $568 \mathrm{ab}$ & $52.1 \mathrm{ab}$ & $449 \mathrm{ab}$ & $18.16 \mathrm{a}$ \\
\hline \multirow[t]{5}{*}{ RC86 } & FI & $2.26 \mathrm{hj}$ & $1.67 \mathrm{cg}$ & $2.02 \mathrm{ef}$ & $3.91 \mathrm{eg}$ & $370 \mathrm{f}$ & $29.4 \mathrm{~h}$ & $321 \mathrm{f}$ & $2.75 \mathrm{~g}$ \\
\hline & MiWS & 3.94 af & $1.83 \mathrm{cf}$ & 1.98 ef & $7.24 \mathrm{ad}$ & 446 e & $36.8 \mathrm{~g}$ & $422 \mathrm{e}$ & $5.73 \mathrm{f}$ \\
\hline & MoWS & $4.36 \mathrm{ad}$ & $1.99 \mathrm{~cd}$ & 1.97 ef & $7.65 \mathrm{ad}$ & $519 \mathrm{~cd}$ & $48.6 \mathrm{de}$ & $426 \mathrm{e}$ & $14.84 \mathrm{~cd}$ \\
\hline & SWS & $5.11 \mathrm{a}$ & $1.96 \mathrm{ce}$ & $1.75 \mathrm{f}$ & $8.45 \mathrm{ac}$ & $541 \mathrm{bc}$ & $50.2 \mathrm{~d}$ & $450 \mathrm{ce}$ & $14.87 \mathrm{~cd}$ \\
\hline & Average & $3.92 \mathrm{bc}$ & $1.86 \mathrm{~b}$ & $1.93 \mathrm{de}$ & $6.31 \mathrm{bc}$ & $469 \mathrm{c}$ & $41.3 \mathrm{c}$ & $405 \mathrm{bc}$ & $9.55 \mathrm{c}$ \\
\hline \multirow[t]{5}{*}{ RC06 } & FI & 3.96 af & $1.73 \mathrm{cg}$ & $1.81 \mathrm{ef}$ & $6.20 \mathrm{ce}$ & $589 \mathrm{ab}$ & $53.1 \mathrm{~d}$ & $436 \mathrm{de}$ & $16.06 \mathrm{c}$ \\
\hline & MiWS & $5.11 \mathrm{a}$ & $1.96 \mathrm{ce}$ & $2.47 \mathrm{df}$ & $7.60 \mathrm{ad}$ & $641 \mathrm{a}$ & $61.3 \mathrm{ac}$ & 449 ce & $21.32 \mathrm{ab}$ \\
\hline & MoWS & $5.15 \mathrm{a}$ & $2.06 \mathrm{bc}$ & $2.56 \mathrm{df}$ & $7.92 \mathrm{ad}$ & $616 \mathrm{a}$ & $64.5 \mathrm{ab}$ & $503 \mathrm{ab}$ & $22.29 \mathrm{a}$ \\
\hline & SWS & $5.20 \mathrm{a}$ & $2.07 \mathrm{bc}$ & $3.86 \mathrm{bc}$ & $8.49 \mathrm{ac}$ & $595 \mathrm{ab}$ & $65.9 \mathrm{ab}$ & $518 \mathrm{a}$ & $22.11 \mathrm{a}$ \\
\hline & Average & $4.85 \mathrm{a}$ & $1.95 \mathrm{~b}$ & $2.67 \mathrm{c}$ & $7.55 \mathrm{ab}$ & $610 \mathrm{a}$ & $61.2 \mathrm{a}$ & $477 \mathrm{a}$ & $20.45 \mathrm{a}$ \\
\hline \multirow[t]{5}{*}{$29 / 2$} & FI & $3.52 \mathrm{bh}$ & $1.42 \mathrm{ch}$ & $1.97 \mathrm{~cd}$ & $3.85 \mathrm{eg}$ & $319 \mathrm{f}$ & $31.0 \mathrm{~h}$ & $337 \mathrm{f}$ & $3.21 \mathrm{~g}$ \\
\hline & MiWS & $3.19 \mathrm{cj}$ & $1.35 \mathrm{ch}$ & $1.52 \mathrm{f}$ & $3.88 \mathrm{eg}$ & 500 ce & $40.4 \mathrm{fg}$ & $416 \mathrm{e}$ & $14.01 \mathrm{~d}$ \\
\hline & MoWS & $3.10 \mathrm{dj}$ & $1.42 \mathrm{ch}$ & $1.94 \mathrm{ef}$ & $4.08 \mathrm{eg}$ & 500 ce & $48.7 \mathrm{de}$ & $431 \mathrm{de}$ & $14.56 \mathrm{~cd}$ \\
\hline & SWS & $3.44 \mathrm{bI}$ & $1.62 \mathrm{cg}$ & 1.97 ef & $5.91 \mathrm{df}$ & $555 \mathrm{bc}$ & $49.3 \mathrm{~d}$ & $447 \mathrm{ce}$ & $15.41 \mathrm{~cd}$ \\
\hline & Average & $3.31 \mathrm{~cd}$ & $1.45 \mathrm{c}$ & $1.79 \mathrm{e}$ & $4.43 \mathrm{~d}$ & $469 \mathrm{c}$ & $42.4 \mathrm{c}$ & $408 \mathrm{bc}$ & $11.80 \mathrm{bc}$ \\
\hline \multirow[t]{5}{*}{ RC9 } & FI & $2.48 \mathrm{gj}$ & $1.88 \mathrm{cf}$ & $1.57 \mathrm{f}$ & $5.76 \mathrm{dg}$ & $471 \mathrm{de}$ & $39.2 \mathrm{fg}$ & $416 \mathrm{e}$ & $6.40 \mathrm{f}$ \\
\hline & MiWS & $2.35 \mathrm{hj}$ & $2.07 \mathrm{bc}$ & $1.69 \mathrm{f}$ & $6.20 \mathrm{ce}$ & $519 \mathrm{~cd}$ & $43.2 \mathrm{ef}$ & 446 c-e & $14.82 \mathrm{~cd}$ \\
\hline & MoWS & $2.56 \mathrm{gj}$ & $1.65 \mathrm{cg}$ & $3.07 \mathrm{ce}$ & $6.63 \mathrm{bd}$ & $599 \mathrm{ab}$ & $58.6 \mathrm{c}$ & $456 \mathrm{~b}-\mathrm{e}$ & $14.23 \mathrm{~cd}$ \\
\hline & SWS & $3.77 \mathrm{bg}$ & $1.67 \mathrm{cg}$ & $3.36 \mathrm{~cd}$ & $6.62 \mathrm{bd}$ & $519 \mathrm{~cd}$ & $60.7 \mathrm{bc}$ & $523 \mathrm{a}$ & $20.98 \mathrm{ab}$ \\
\hline & Average & $2.79 \mathrm{de}$ & $1.82 \mathrm{~b}$ & $2.42 \mathrm{~cd}$ & $6.30 \mathrm{bc}$ & $529 \mathrm{~b}$ & $50.4 \mathrm{~b}$ & $460 \mathrm{a}$ & $14.11 \mathrm{~b}$ \\
\hline \multirow[t]{4}{*}{ Average } & FI & $2.76 \mathrm{c}$ & $1.57 \mathrm{~b}$ & $2.00 \mathrm{c}$ & $5.04 \mathrm{~d}$ & $450 \mathrm{~b}$ & $38.7 \mathrm{c}$ & $377 \mathrm{~d}$ & $7.96 \mathrm{~d}$ \\
\hline & MiWS & $3.27 \mathrm{bc}$ & $1.74 \mathrm{ab}$ & $2.60 \mathrm{bc}$ & $5.90 \mathrm{~cd}$ & $514 \mathrm{a}$ & $44.6 \mathrm{~b}$ & $411 \mathrm{c}$ & $11.67 \mathrm{c}$ \\
\hline & MoWS & $3.54 \mathrm{ab}$ & $1.75 \mathrm{ab}$ & $3.06 \mathrm{ab}$ & $6.74 \mathrm{ab}$ & $524 \mathrm{a}$ & $48.1 \mathrm{~b}$ & $448 \mathrm{~b}$ & $15.90 \mathrm{~b}$ \\
\hline & SWS & $4.06 \mathrm{a}$ & $1.87 \mathrm{a}$ & $3.34 \mathrm{a}$ & $7.52 \mathrm{a}$ & $539 a$ & $54.5 \mathrm{a}$ & $494 \mathrm{a}$ & $19.46 \mathrm{a}$ \\
\hline
\end{tabular}

Notes. ${ }^{1}$ - bacterial strains and water regimes are explained in Table 1 and under Table 2; GR - glutathione reductase, GST - glutathione S-transferase, G6PD - glucose-6-phosphate dehydrogenase, 6PGD - 6-phosphogluconate dehydrogenase; CAT catalase, POD - peroxidase, SOD - superoxide dismutase, APX - ascorbate peroxidise; FW - fresh weight. ${ }^{2}$ - values followed by different lower-case letters in a column (each section separately) were significantly different $(P \leq 0.05)$.

while the corresponding increase in lipid peroxidation was $79.7 \%$. The increase in the yield loss was nearly twofold in the control plants exposed to severe drought stress compared to the well-watered plants. However, under drought stress conditions, the presence of RC77, RC35 and RC9 reduced MDA levels, indicating that these strains imparted considerable protection against oxidative damage of lipids. The accumulation of MDA content was lowest in the treatment RC35 followed by RC77 revealing reduced accumulation of lipid peroxides under drought stress. PGPR inoculation has been shown to reduce the negative effects of drought stress. As MDA and $\mathrm{H}_{2} \mathrm{O}_{2}$ decreased, strawberry growth, yield and chlorophyll contents increased. Yield of strawberry negatively and significantly correlated $(p \leq 0.01)$ with MDA $(r=-0.54 * *)$ and $\mathrm{H}_{2} \mathrm{O}_{2}(r=-0.53 * *)$ contents. Also, yield $\left(r=0.35^{* *}\right)$ was positively correlated with chlorophyll contents.

\section{Discussion}

Under insufficient water supply, the weight of berries, titratable acidity, chlorophyll contents, and macro- and micro-nutrient concentrations were lower than under well-watered conditions. The results showed that by increasing water-deficit stress, chlorophyll contents 

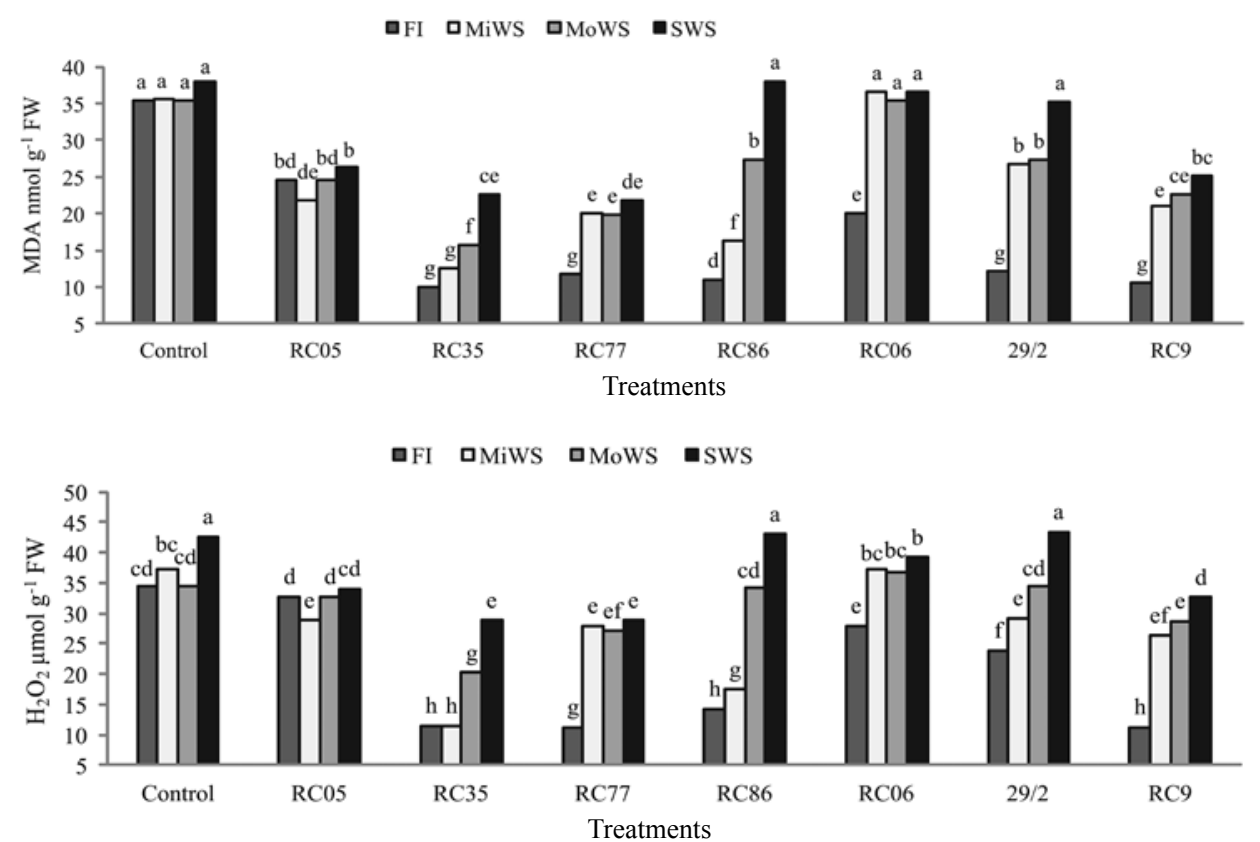

Note. Values with different letters are significantly different at $p \leq 0.05$ (Duncan's test); FW - fresh weight; water regimes and bacterial strains are explained under Table 2 and in Table 1.

Figure 2. Effect of different irrigation regimes and bacterial applications on malondialdehyde (MDA) and hydrogen peroxide $\left(\mathrm{H}_{2} \mathrm{O}_{2}\right)$ content in strawberry leaves

decrease, which leads to less yield and growth. Deficit irrigation in strawberry fruits is generally associated with reduction in berry size and yield; however, a recent study demonstrated that reducing water irrigation on strawberry can increase the concentration of some taste- and healthrelated compounds in fruits (Bordonaba, Terry, 2010).

Leaf chlorophyll, fresh berry yield, individual berry fresh weight, and titratable acidity were significantly lower in the plants that are under moderate and severe drought stress than those under full irrigation; whereas the total number of berry per plant was higher under severe drought stress. Previous studies also showed that fruits from strawberry plants that received full irrigation had a higher water content and greater berry fresh weight than fruits from plants grown under reduced irrigation (Liu et al., 2007; Terry et al., 2007; Bordonaba, Terry, 2010; Ipek et al., 2014). Water stress has a great influence on the plant photosynthetic capacity of strawberry (Mao et al., 2009). Other authors have also reported that smaller fruit resulted from reduced irrigation (Terry et al., 2007).

Decreasing water availability under drought generally results in the reduced total nutrient uptake and frequently reduced concentrations of mineral nutrients in crop plants. Drought stress also decreased macroand micro-nutrient concentrations in strawberry leaves $\mathrm{P}, \mathrm{K}, \mathrm{S}$ and $\mathrm{Ca}$ uptake of strawberry cultivar 'Aromas', whereas application of PGPR increased the uptake of all of these elements. Reduced plant growth caused by drought may be attributed to a disturbance in the nutrients of plants, resulting from the decreased uptake of mineral nutrients. Strawberry plants inoculated with three PGPR strains (RC05, RC9 and RC77) generally grew better and had higher N, P, K, Fe and Mn uptake and berry yield than plants inoculated with other strains and the control (Tables 2-3). K nutrition can improve drought resistance (Wang et al., 2013). Results of several studies indicate that application of PGPR increased the growth, nutrient element content, and yield of strawberry plants (Esitken et al., 2010; Ipek et al., 2014).
The activities of the anti-oxidative enzymes such as GR, GST, CAT, POD, SOD and APX increased under water-deficit stress in the plants. These results are in agreement with those of other researchers (Wu et al., 2006), who reported that the activities of SOD, POD, CAT, APX and GR increased under drought stress. Plant cells stimulate different antioxidant enzymes such as CAT, POD, SOD and APX that eliminate these reactive free radicals or suppress their formation (Simova-Stoilova et al., 2008). These results suggest that the activities of SOD, POD and CAT, and contents of $\mathrm{H}_{2} \mathrm{O}_{2}$ and MDA are the most important traits for plants' ability to survive under drought stress (Zhang et al., 2011). Increase in SOD, POD, CAT and APX activities in plant leaves under drought conditions has also been reported by Patel and Hemantaranjan (2012).

In the present study the CAT, POD, SOD and APX activity as well as the MDA content and $\mathrm{H}_{2} \mathrm{O}_{2}$ levels increased with the increasing levels of water deficit in both the PGPR inoculated and the un-inoculated plants. Thus, increased stress tolerance in PGPR inoculated plants could be correlated with the higher total phenolics content, antioxidant capacity and antioxidant enzyme activity. It has been found that strawberry plants inoculated with multitraits PGPR strains showed high antioxidant enzymes activity which contributed to enhance the plant protection against drought stress. In addition, plants inoculated with ACC deaminase-containing PGPR significantly lowered the level of ACC in the stressed plants, thereby lowering the amount of stress ethylene synthesis and hence damage to the plant (Zahir et al., 2008). Reduction of oxidative stress is correlated with drought stress tolerance induced by plant-beneficial bacteria (Compant et al., 2010).

Water deficit treatment significantly increased MDA and $\mathrm{H}_{2} \mathrm{O}_{2}$ accumulation, which indicated the extent of oxidative injury posed by stress conditions. MDA and $\mathrm{H}_{2} \mathrm{O}_{2}$ levels were increased by drought stress both in inoculated and in non-inoculated plants. Four of the PGPR strains (RC05, RC35, RC77 and RC9) exhibiting 
better performance under water deficit conditions have been observed to have lower levels of MDA content in the shoot which correlated well with their decreased $\mathrm{H}_{2} \mathrm{O}_{2}$ content (Fig. 2) and enhanced total phenolics and antioxidant capacity (Fig. 1), thus protecting the plants from lipid peroxidation of membrane systems as compared to the other bacteria and control which had higher levels of MDA content. These results indicated that water-stressed $\mathrm{RC} 05, \mathrm{RC} 35, \mathrm{RC} 77$ and $\mathrm{RC} 9$ plants showed much less oxidative damage (reduced MDA and $\mathrm{H}_{2} \mathrm{O}_{2}$ content) compared with water-stressed control plants. Drought stress and bacterial application increased enzyme activities, and TPC content, whereas effective bacterial strains such as RC35, RC77 and RC9 decreased MDA and $\mathrm{H}_{2} \mathrm{O}_{2}$ content. It induced the activity of enzymes, alleviated membrane lipid peroxidation as well as membrane system damage, thus improving the drought resistance of strawberry (Sun et al., 2013). Our findings showed an increase in MDA and $\mathrm{H}_{2} \mathrm{O}_{2}$ in both well-watered and drought-stressed plants though increase was less evident in the PGPR-treated strawberry plants. The PGPR could induce plant growth and development, reduce stress susceptibility, and may contribute to the concept of biotechnology application in agriculture.

\section{Conclusions}

1. Bacterial inoculation minimized the drought stress-imposed effects significantly increasing the fresh berry yield, individual berry fresh weight, and titratable acidity, chlorophyll content, and macro- and micronutrient concentrations in strawberry leaves. Considering all the results together, it was observed that the strawberry cultivar 'Aromas' which showed better seedling growth accompanied by increased activities of both the enzymes and decreased contents of malondialdehyde (MDA) and hydrogen peroxide $\left(\mathrm{H}_{2} \mathrm{O}_{2}\right)$, under water deficit conditions, performed much better and thus exhibited higher stress resistance.

2. Changes in plant total phenolics content (TPC), trolox equivalent antioxidant capacity (TEAC), MDA and $\mathrm{H}_{2} \mathrm{O}_{2}$ content, CAT, POD, SOD, APX, GST and GR activities as a result of inoculant application would be useful markers for the bacterial effect on the strategies of drought tolerance in these plants. Plant growthpromoting rhizobacteria (PGPR) has played critical roles in strawberry responses to stress and alleviated droughtinduced oxidative stress.

3. Our results provide strong evidence that the role of PGPR in the performance of strawberry plants in stressful environment of soils.

4. In spite of the evident relation among plant growth, chlorophyll contents and drought tolerance, the influence of PGPR on plant drought tolerance was also based on mechanisms independent of multiple plant growth-promotion traits.

5. The selected ACC deaminase-containing, IAA-producing, $\mathrm{N}_{\text {-fixing }}$ and P-solubilizing PGPR strains, such as RCO5, RC9, RC35 and RC77 could play an important role in understanding plant tolerance to stress, adaptation to stress and mechanisms that develop in plants under stress conditions, and could be practical and effective application in protecting different plant species against drought stress.

\section{Acknowledgements}

This study was supported by Ataturk University BAP Commission (2010/293).

Received 14072015 Accepted 20012016

\section{References}

Bordonaba J. G., Terry L. A. 2010. Manipulating the tasterelated composition of strawberry fruits (Fragaria $\times$ ananassa) from different cultivars using deficit irrigation. Food Chemistry. 122: 1020-1026 http://dx.doi.org/10.1016/j.foodchem.2010.03.060

Bremner J. M. 1996. Nitrogen-total. Bartels J. M., Bigham J. M. (eds). Methods of soil analysis. Part 3: Chemical Methods. SSSA, Madison, USA, p. 1085-1121

Bresson J., Varoquaux F., Bontpart T., Touraine B., Vile D. 2013. The PGPR strain Phyllobacterium brassicacearum STM196 induces a reproductive delay and physiological changes that result in improved drought tolerance in Arabidonsis. New Phytologist. 200: 558-569 http://dx.doi.org/10.1111/nph.12383

Çakmakçı R., Erat M., Erdoğan U., Donmez F. 2007. The influence of plant growth-promoting rhizobacteria on growth and enzyme activities in wheat and spinach plants. Journal of Plant Nutrition and Soil Science, 170: 288-295 http://dx.doi.org/10.1002/jpln.200625105

Çakmakçı R., Erat M., Oral B., Erdogan U., Şahin F. 2009. Enzyme activities and growth promotion of spinach by indole-3-acetic acid-producing rhizobacteria. Journal of Horticultural Science and Biotechnology, 84: 375-380

Çakmakçı R., Donmez F., Ertürk Y., Erat M., Haznedar A., Sekban R. 2010. Diversity and metabolic potential of culturable bacteria from the rhizosphere of Turkish tea grown in acidic soils. Plant and Soil. 332 (1-2): 299-318 http://dx.doi.org/10.1007/s11104-010-0295-4

Chikezie P. C., Chikezie C. M., Uwakwe A. A., Monako C. C. 2009. Comparative study of glutathione S-transferase activity of three human erythrocyte genotypes infected with plasmodium falciparum. Journal of Applied Sciences and Environmental Management, 13: 13-18

Compant S., van der Heijden M. G. A., Sessitsch A. 2010. Climate change effects on beneficial plant-microorganism interactions. FEMS Microbiology Ecology, 73: 197-214 http://dx.doi.org/10.1111/j.1574-6941.2010.00900.x

Dai J., Mumper R. J. 2015. Plant phenolics: extraction, analysis and their antioxidant and anticancer properties. Molecules, 15: 7313-7352 http://dx.doi.org/10.3390/molecules15107313

Esitken A., Yildiz H. E., Ercisli S., Donmez F., Turan M., Gunes A. 2010. Effects of plant growth promoting bacteria (PGPB) on yield, growth and nutrient contents of organically grown strawberry. Scientia Horticulturae. 124: 62-66 http://dx.doi.org/10.1016/j.scienta.2009.12.012

Giannakoula A. E., Ilias I. F., Maksimović J. J. D., Maksimović V. M., Zivanović B.D. 2012. The effects of plant growth regulators on growth, yield, and phenolic profile of lentil plants. Journal of Food Composition and Analvsis. 28: 46-53 http://dx.doi.org/10.1016/j.jfca.2012.06.005

Gill S. S., Iuteja N. 2010. Reactive oxygen species and antioxidant machinery in abiotic stress tolerance in crop plants. Plant Physiology and Biochemistry, 48: 909-930 http://dx.doi.org/10.1016/j.plaphy.2010.08.016

Guo X. Y., Zhang X. S., Huang Z. Y. 2010. Drought tolerance in three hybrid poplar clones submitted to different watering regimes. Journal of Plant Ecology, 3: 79-87 http://dx.doi.org/10.1093/jpe/rtq007

Gündüz K., Özdemir E. 2014. The effects of genotype and growing conditions on antioxidant capacity, phenolic compounds, organic acid and individual sugars of strawherry. Food Chemistry. 155: 298-303 http://dx.doi.org/10.1016/j.foodchem.2014.01.064

Heiadari M., Golpayegani A. 2012. Etfects of water stress and inoculation with plant growth promoting rhizobacteria (PGPR) on antioxidant status and photosynthetic pigments in basil (Ocimum basilicum L.). Journal of the Saudi Society of Agricultural Sciences, 11: 57-61 http://dx.doi.org/10.1016/j.jssas.2011.09.001

Ipek M., Pirlak L., Esitken A., Donmez M. F., Turan M., Sahin F. 2014. Plant growth-promoting rhizobacteria (PGPR) increase yield, growth and nutrition of strawberry under high-calcareous soil conditions. Journal of Plant Nutrition, 37: 990-1001 http://dx.doi.org/10.1080/01904167.2014.881857 
Liu F., Savic S., Jensen C. R., Shahnazari A., Jacobsen S. E., Stikic R., Andersen M. N. 2007. Water relations and yield of lysimeter grown strawberries under limited irrigation. Scientia Horticulturae. 111: 128-132 http://dx.doi.org/10.1016/j.scienta.2006.10.006

Mao S. Y., Jiang C. D., Zhang W. H., Shi L., Zhang J. Z., Chow W. S., Yang J. C. 2009. Water translocation between ramets of strawberry during soil drying and its effects on photosynthetic nerformance. Phvsiologia Plantarum. 137: 225-234 http://dx.doi.org/10.1111/j.1399-3054.2009.01275.x

Minucci A., Giardina B., Zuppi C., Capoluongo E. 2009. Glucose-6-phosphate dehydrogenase laboratory assay: how, when, and why? IUBMB Life, 61: 27-34 http://dx.doi.org/10.1002/iub.137

Nikolaeva M. K., Maevskaya S. N., Shugaev A. G., Bukhov N. G. 2010. Effect of drought on chlorophyll content and antioxidant enzyme activities in leaves of three wheat cultivars varying in productivity. The Russian Journal of Plant Phvsiologv. 57: 87-95 http://dx.doi.org/10.1134/S1021443710010127

Patel P. K., Hemantaranjan A. 2012. Antioxidant defence system in chickpea (Cicer arietinum L.): influence by drought stress implemented at pre- and post-anthesis stage. American Journal of Plant Physiologv. 7: 164-173 http://dx.doi.org/10.3923/ajpp.2012.164.173

Sairam R. K., Srivastava G. C. 2002. Changes in antioxidant activity in sub-cellular fractions of tolerant and susceptible wheat genotypes in response to long term salt stress. Plant Science. 162: 897-904 http://dx.doi.org/10.1016/S0168-9452(02)00037-7

Saleem M., Arshad M., Hussain S., Bhatti A. S. 2007. Perspective of plant growth promoting rhizobacteria (PGPR) containing ACC deaminase in stress agriculture. The Journal of Industrial Microbiology and Biotechnology. 34: 635-648 http://dx.doi.org/10.1007/s10295-007-0240-6

Simova-Storlova L., Demirevska K., Petrova I., Tsenov N., Feller U. 2008. Antioxidative protection in wheat varieties under severe recoverable drought at seedling stage. Plant, Soil and Environment, 54: 529-536

ISSN 1392-3196 / e-ISSN 2335-8947

Zemdirbyste-Agriculture, vol. 103, No. 1 (2016), p. 67-76

DOI $10.13080 / z-a .2016 .103 .009$
Song J., Dub L., Lic L., Kalta W., Palmera L. C., Fillmorea S., Zhangd Y., Zhangb Z., Lic X. 2015. Quantitative changes in proteins responsible for flavonoid and anthocyanin biosynthesis in strawberry fruit at different ripening stages: a targeted quantitative proteomic investigation employing multinle reaction monitoring. Journal of Proteomics, 122: 1-10 http://dx.doi.org/10.1016/j.jprot.2015.03.017

Sun C. H., Wang D., Hu Y. L., Li X. H., Zhang W. D., Sun J., Gao X. L. 2013. Effects of salicylic acid on physiological characteristics of strawberry leaves under drought stress. ve, 78: 106-111

Sun S., Li M., Zuo J. H, Jiang W. S, Liu D. H. 2015. Cadmium effects on mineral accumulation, antioxidant defence system and gas exchange in cucumber. ZemdirbysteAgriculture. 102 (2): 193-200 http://dx.doi.org/10.13080/z-a.2015.102.025

Terry L. A., Chope G. A., Bordonaba J. G. 2007. Effect of water deficit irrigation and inoculation with Botrytis cinerea on strawberry (Fragaria $\times$ ananassa) fruit quality. Journal of Agricultural and Food Chemistry, 55: 10812-10819 http://dx.doi.org/10.1021/jf072101n

Wang M., Zheng Q. S., Shen Q. R., Guo S. W. 2013. The critical role of potassium in plant stress response. International Journal of Molecular Sciences, 14: 7370-7390 http://dx.doi.org/10.3390/ijms 14047370

Wu Q. S., Zou Y. N., Xia R. X. 2006. Effects of water stress and arbuscular mycorrhizal fungi on reactive oxygen metabolism and antioxidant production by citrus (Citrus tangerine) roots. The Euronean Journal of Soil Biology. 42: 166-172 http://dx.doi.org/10.1016/j.ejsobi.2005.12.006

Zahir Z. A., Munir A., Asghar H. N., Shaharoona B., Arshad M. 2008. Effectiveness of rhizobacteria containing ACC deaminase for growth promotion of peas (Pisum sativum) under drought conditions, Journal of Microbiology and Biotechnology, 18: 858-96

Zhang L. X., Wang K., Zhang X. F., Lu L. X., Li Y. F., Gao M., Wang C. Y., Hu J. J., Liang Z. S. 2011. Role of nitrate nutrition in alleviation of the adverse effects of drought stress on maize cultivars: biomass production and antioxidative capacity. Pakistan Journal of Botany, 43: $2869-2874$

\title{
Augimą skatinančiomis rizobakterijomis inokuliavimo įtaka braškėms esant vandens stygiaus stresui
}

\author{
Ü. Erdogan ${ }^{1}$, R. Çakmakçi ${ }^{1}$, A. Varmazyari', M. Turan², Y. Erdogan'1 , N. Kitir ${ }^{2}$ \\ ${ }^{1}$ Atatürk universitetas, Turkija \\ ${ }^{2}$ Yeditepe universitetas, Turkija
}

\section{Santrauka}

Tyrimas atliktas 2011 ir $2012 \mathrm{~m}$. Vegetaciniuose induose ịvertinta bakterijų, turinčių 1-aminociklopropano-1karboksilato (ACC) deaminazès, fiksuojančių $\mathrm{N}_{2}$ ir tirpinančių Pjunginius įtaka braškių derliui ir morfofiziologiniams rodikliams. Aštuoni inokuliavimo bakterijomis variantai su keturiais vandens režimais buvo išdèstyti atsitiktine tvarka. Dèl mažejjančio aprūpinimo vandeniu palaipsniui mažèjo augalų augimas, chlorofilo kiekis bei uogų derlius ir braškių lapuose didejo sausros streso žymeklių bendras fenolių kiekis (TPC), trolokso ekvivalento antioksidacinė geba (TEAC), malondialdehido (MDA) kiekis, vandenilio peroksido $\left(\mathrm{H}_{2} \mathrm{O}_{2}\right)$, glutationo reductazès (GR), glutationo S-transferazès (GST), katalazès (CAT), peroksidazès (POD), superoksidazès dismutazès (SOD) ir askorbato peroksidazès (APX) aktyvumas. Bakterijos taip pat padidino augalų augimą ir TPC, TEAC, antioksidacinių fermentu (GR, GST, CAT, POD, SOD ir APX) aktyvumą, fitohormonų (GA, SA ir IAA) ir N, P, K, Ca, Fe, Mn, Zn bei $\mathrm{Cu}$ kiekius, bet sumažino MDA ir $\mathrm{H}_{2} \mathrm{O}_{2}$ kiekius, kurie iš dalies galèjo suaktyvinti fiziologinius ir biocheminius procesus, mažinančius sausros streso poveikį.

Reikšminiai žodžiai: augalų augimą skatinančios bakterijos, fermentų veikla, Fragaria $\times$ ananassa, maisto medžiagų ịsisavinimas, sausros stresas.

Please use the following format when citing the article:

Erdogan U., Cakmakci R., Varmazyari A., Turan M., Erdogan Y., Kitir N. 2016. Role of inoculation with multi-trait rhizobacteria on strawberries under water deficit stress. Zemdirbyste-Agriculture, 103 (1): 67-76 DOI 10.13080/z-a.2016.103.009 